\title{
A Toxoplasma gondii Oxopurine Transporter Binds Nucleobases and Nucleosides Using Different Binding Modes
}

\author{
Gustavo D. Campagnaro ${ }^{1}{ }^{\mathbb{D}}$, Hamza A. A. Elati ${ }^{1}$, Sofia Balaska ${ }^{1}$, Maria Esther Martin Abril ${ }^{1}$, Manal J. Natto ${ }^{1}$, \\ Fabian Hulpia ${ }^{2} \mathbb{D}$, Kelly Lee ${ }^{1}$, Lilach Sheiner ${ }^{1,3}{ }^{1}$, Serge Van Calenbergh ${ }^{2} \mathbb{D}$ and Harry P. de Koning ${ }^{1, * \mathbb{D}}$
}

1 Institute of Infection, Immunity and Inflammation, College of Medical, Veterinary and Life Sciences, University of Glasgow, Glasgow G12 8TA, UK; campagnarogd@gmail.com (G.D.C.); 2218613e@student.gla.ac.uk (H.A.A.E.); sofia_balaska@imbb.forth.gr (S.B.); estermartin95@gmail.com (M.E.M.A.); Manal.Natto@glasgow.ac.uk (M.J.N.); Kelly.lee14@outlook.com (K.L.); lilach.sheiner@glasgow.ac.uk (L.S.)

2 Laboratory for Medicinal Chemistry, Campus Heymans, Ghent University, Ottergemsesteenweg 460, B-9000 Gent, Belgium; fhulpia@its.jnj.com (F.H.); serge.vancalenbergh@ugent.be (S.V.C.)

3 Wellcome Centre for Integrative Parasitology, College of Medical, Veterinary and Life Sciences, University of Glasgow, Glasgow G12 8TA, UK

* Correspondence: Harry.de-Koning@glasgow.ac.uk; Tel.: +44-141-3303753

\section{check for

Citation: Campagnaro, G.D.; Elati,

H.A.A.; Balaska, S.; Martin Abril,

M.E.; Natto, M.J.; Hulpia, F.; Lee, K.; Sheiner, L.; Van Calenbergh, S.; de Koning, H.P. A Toxoplasma gondii Oxopurine Transporter Binds

Nucleobases and Nucleosides Using Different Binding Modes. Int. J. Mol. Sci. 2022, 23, 710. https://doi.org/ $10.3390 /$ ijms 23020710

Academic Editor: Alexande Baykov

Received: 15 December 2021

Accepted: 7 January 2022

Published: 10 January 2022

Publisher's Note: MDPI stays neutral with regard to jurisdictional claims in published maps and institutional affiliations.

Copyright: (C) 2022 by the authors. Licensee MDPI, Basel, Switzerland. This article is an open access article distributed under the terms and conditions of the Creative Commons Attribution (CC BY) license (https:// creativecommons.org/licenses/by/ $4.0 /$ )

\begin{abstract}
Toxoplasma gondii is unable to synthesize purines de novo, instead salvages them from its environment, inside the host cell, for which they need high affinity carriers. Here, we report the expression of a T. gondii Equilibrative Nucleoside Transporter, Tg244440, in a Trypanosoma brucei strain from which nucleobase transporters have been deleted. $\mathrm{Tg} 244440$ transported hypoxanthine and guanine with similar affinity $\left(K_{\mathrm{m}} \sim 1 \mu \mathrm{M}\right)$, while inosine and guanosine displayed $K_{\mathrm{i}}$ values of 4.05 and $3.30 \mu \mathrm{M}$, respectively. Low affinity was observed for adenosine, adenine, and pyrimidines, classifying $\operatorname{Tg} 244440$ as a high affinity oxopurine transporter. Purine analogues were used to probe the substrate-transporter binding interactions, culminating in quantitative models showing different binding modes for oxopurine bases, oxopurine nucleosides, and adenosine. Hypoxanthine and guanine interacted through protonated N1 and N9, and through unprotonated N3 and N7 of the purine ring, whereas inosine and guanosine mostly employed the ribose hydroxy groups for binding, in addition to $\mathrm{N} 1 \mathrm{H}$ of the nucleobase. Conversely, the ribose moiety of adenosine barely made any contribution to binding. $T g 244440$ is the first gene identified to encode a high affinity oxopurine transporter in T. gondii and, to the best of our knowledge, the first purine transporter to employ different binding modes for nucleosides and nucleobases.
\end{abstract}

Keywords: Toxoplasma gondii; purine transporter; $\mathrm{Tg} 244440$; nucleobase transporter; apicomplexan; substrate binding

\section{Introduction}

Toxoplasma gondii is probably one of the most successful parasites in the world and it is thought to be potentially infective for all warm-blooded land and sea animals. The infection occurs predominantly by ingestion of: meat containing tissue cysts harboring bradyzoites; milk containing tachyzoites; or water or sward contaminated with sporulated oocysts. After ingestion, the parasites penetrate the intestinal tissue, differentiate into tachyzoites and multiply intracellularly by endodyogeny before disseminating to other tissues [1,2]. Infection by T. gondii can be lethal for some species of marsupials and sea mammals [3], but in most hosts it is effectively controlled by the immune response and the presence of the parasite is restrained to latent cysts formed in muscle and nervous tissues $[1,2,4,5]$.

Toxoplasmosis highly impacts livestock production by causing abortions in sheep, goats, and pigs, as well as causing diarrhea and anorexia in pigs, which causes the loss of 
several millions of dollars every year [6]. On top of that, livestock infections very much contribute to human infections as the consumption of meat containing T. gondii tissue cysts likely represents the most important source for horizontal transmission to human subjects [2].

Around one-third of the human population is infected by the parasite, but most people are asymptomatic or present mild flu-like symptoms [1]. The complications associated with toxoplasmosis arise predominantly from congenital transmission, especially when first infection with Toxoplasma occurs within the first trimester of pregnancy, or after immunosuppression of infected subjects. Vertical transmission during pregnancy often causes miscarriages, death in the uterus, or congenital birth defects such as encephalitis, hydrocephalus, and retinochoroiditis, among others $[1,7]$. In the case of newly immunocompromised individuals, the decrease in immunocompetence allows the persistent bradyzoites to burst the cyst wall, transform into tachyzoites and once more disseminate around the body, causing encephalitis or retinochoroiditis [1,4]. In fact, toxoplasmosis is the most common infection of the central nervous system in HIV-positive patients [4].

Thus, the current approach to contain toxoplasmosis remains based on chemotherapy, which targets the parasite's synthesis of folate. Such chemotherapy combines inhibitors of dihydrofolate reductase and dihydrofolate synthase, most notably pyrimethamine (PYR) and sulfadiazine (SULF), respectively, while supplementing with folinic acid to mitigate the toxic effects of PYR [8,9]. The drawbacks with such regimens are toxicity, poor tolerance by immunocompromised patients, prolonged treatment courses, and inefficacy against the latent stage of the parasite [8,9]. Drug resistance can be achieved in vitro and has been reported in clinical isolates [10]. All this highlights the need for the development of new and more effective chemotherapeutical agents with different mechanisms of action against T. gondii or for better treatment schemes using currently approved drugs [9-11].

The fact that all protozoan parasites studied to date are incapable of producing their own purines, and thus rely on salvage from the host, reinforces the idea of using purine analogues as chemotherapeutical agents against protozoal infections [12,13]. In apicomplexan parasites, the search for purine analogues with chemotherapeutical potential has mainly focused on permeants of the Equilibrative Nucleoside Transporter (ENT) 1 of Plasmodium falciparum, the most important (and essential) carrier for purine uptake in this parasite $[12,14,15]$. However, much less attention has been given to T. gondii ENTs, and only a few nucleoside analogues with low micromolar anti-Toxoplasma activity have been described to date, specifically 6-benzylthioinosine and its analogues [16-21]. In addition, there is one study on the parasitostatic effect of 6-thioxanthine [22] and adenine arabinoside (Ara-A), known to be moderately active against $T$. gondii [23]. Most promising, $2^{\prime}, 3^{\prime}$-dideoxyinosine, which is part of the highly active antiretroviral therapy (HAART) used for HIV-infected patients, has been shown to be active in vitro and in vivo against $T$. gondii [24-26].

The antiprotozoal activity of nucleoside analogues depends on their efficient internalization by the parasite and on their affinity for specific metabolic enzymes that activate the analogue or are inhibited by it. The initial studies on $T$. gondii purine transporters by Schwab et al. [27] revealed the existence of at least two transport mechanisms in this parasite, one of which was characterized as a low-affinity adenosine transporter (TgAT1; $K_{\mathrm{m}}$ $120 \mu \mathrm{M})$. The gene believed to encode for TgAT1 was cloned from an adenine arabinosideresistant strain and expressed in Xenopus laevis oocytes, revealing it had similar affinities for inosine, formycin B and allopurinol riboside [28]. The sequence encoding TgAT1 is annotated as $\mathrm{Tg} 244440$ in ToxoDB but in this manuscript we will distinguish between the observed low affinity adenosine transport in T. gondii tachyzoites, TgAT1, and our result with the expressed sequence $\mathrm{Tg} 244440$, so as not to presume a priori that all phenotypic observations assigned to 'TgAT1' are necessarily linked to Tg244440. TgAT1 was also identified in isolated tachyzoites by De Koning et al. [29] who further described the presence of high-affinity adenosine $\left(\mathrm{TgAT} 2 ; K_{\mathrm{m}} 0.49 \mu \mathrm{M}\right)$ and hypoxanthine $\left(\mathrm{TgNBT} 1 ; K_{\mathrm{m}} 0.91 \mu \mathrm{M}\right)$ transporters. It is important that TgAT2 was shown to be a broad specificity nucleoside 
transporter that recognizes several nucleoside analogues, and is the only T. gondii purine transporter for which a substrate binding model has been reported, allowing the rational optimization of analogues with high transport efficiency on this carrier [29].

It is interesting to notice, thus, that although TgAT2 has higher affinity for adenosine than TgAT1 and seems to have broader substrate selectivity, resistance to Ara-A was acquired after loss of TgAT1 [28]. Therefore, we decided to investigate the mode of interaction of TgAT1/Tg244440 with its substrates. To do so, we used a gain-of-function approach utilizing T. brucei as the expression system, as previously done by us for ENT family transporters of T. congolense, T. cruzi, Leishmania spp. and Trichomonas vaginalis [30-33]. We found Tg244440 to have high affinity for oxopurine nucleobases and nucleosides and only low affinity for aminopurines and pyrimidines. The very high affinity for both oxopurine nucleosides and nucleobases is highly unusual and the binding modes were carefully investigated using a series of selected matched pair analogues. We conclude that the nucleosides and nucleobases bind in different orientations in the Tg244440 binding pocket.

\section{Results}

2.1. Equilibrative Nucleoside Transporters from Coccidian Parasites form a Separate Phylogenetic Cluster within the Family

We have previously shown that it was possible to predict the substrate selectivity of Trypanosoma cruzi ENT transporters by analysing their phylogenetic alignment with ENTs from other kinetoplastids [32]. Figure 1A shows a phylogenetic tree of nucleoside and nucleobase transporters from a number of different gene families. Transporters belonging to Nucleoside-Cation Symporter 1 (NCS1) and Nucleobase-Ascorbate Transporter (NAT, also known as NCS2), both belonging to the Amino acid-Polyamine-Organocation (APC) superfamily were positioned in a separate branch, but forming two distinct clusters. Members of the Concentrative Nucleoside Transporter (CNT) family formed a separate branch close to the NCS1 transporters as did AzgA-like transporters, although recent analyses have proposed AzgA-like transporters are associated with the NAT family [34,35]. It is probable that the higher number of ENT sequences used for the construction of the phylogenetic tree caused the positioning of AzgA-like and CNT transporters close to the NCS1 cluster.

The ENT sequences formed a consistent branch, with separations between the sequences from trypanosomatids (T. brucei and Leishmania spp.), humans and apicomplexans (Figure 1B). Among trypanosomatids, which are the best studied protozoans in terms of purine and pyrimidine transport, there was a clear separation between purine nucleoside (T. brucei P1 and P2 and Leishmania NT2 clusters) and nucleobase (T. brucei NT8 and Leishmania NT3 and NT4 clusters) transporters, with the purine/pyrimidine nucleoside Leishmania NT1 transporters forming an outside group within this branch (Figure 1B). This consistent grouping of transporter sequences with their known activities indicates a high level of predictability in the tree. The apicomplexan ENTs formed a separate group within the ENT family, with a separation between sequences from P. falciparum and coccidian apicomplexans (T. gondii, Hammondia hammondi, Cystoisospora suis and Sarcocystis neurona), indicating apparent gene proliferation from a common ancestral ENT gene after divergence of Plasmodium and coccidian species, but $T$. gondii sequences (Figure 1B; black stars) always clustered very closely to their homologues in H. hammondi, its closest relative [36]. Moreover, our phylogenetic analysis indicates that $\mathrm{Tg} 244440$ (and its homologue in H. hammondi) was the most distant of the ENT sequences found in coccidia (Figure 1A; red star), being at the edge of the ENT clade. We also observed an extraordinary conservation of the $\mathrm{Tg} 244440$ protein sequence among T. gondii strains: of the sequences retrieved from 15 strains, only one amino acid change (Leu $\rightarrow$ Phe in position 304) in Tg244440 was observed and only in strain MAS (Supplementary Figure S1). This high a level of conservation was not observed for any other T. gondii ENT transporter. Full-length Tg288540 (696 a.a.) was present in 14/15 of these strains, with the allele in strain TgRUB lacking the N-terminal 272 a.a.; Tg233230 (531 a.a.) was found in all 15 strains and displayed four amino acid changes; Tg359630 was found in only $11 / 15$ strains available at ToxoDB, and displayed six amino acid changes 
within those sequences, while lacking the N-terminal 308 a.a. in strain RH (Supplementary File S1).
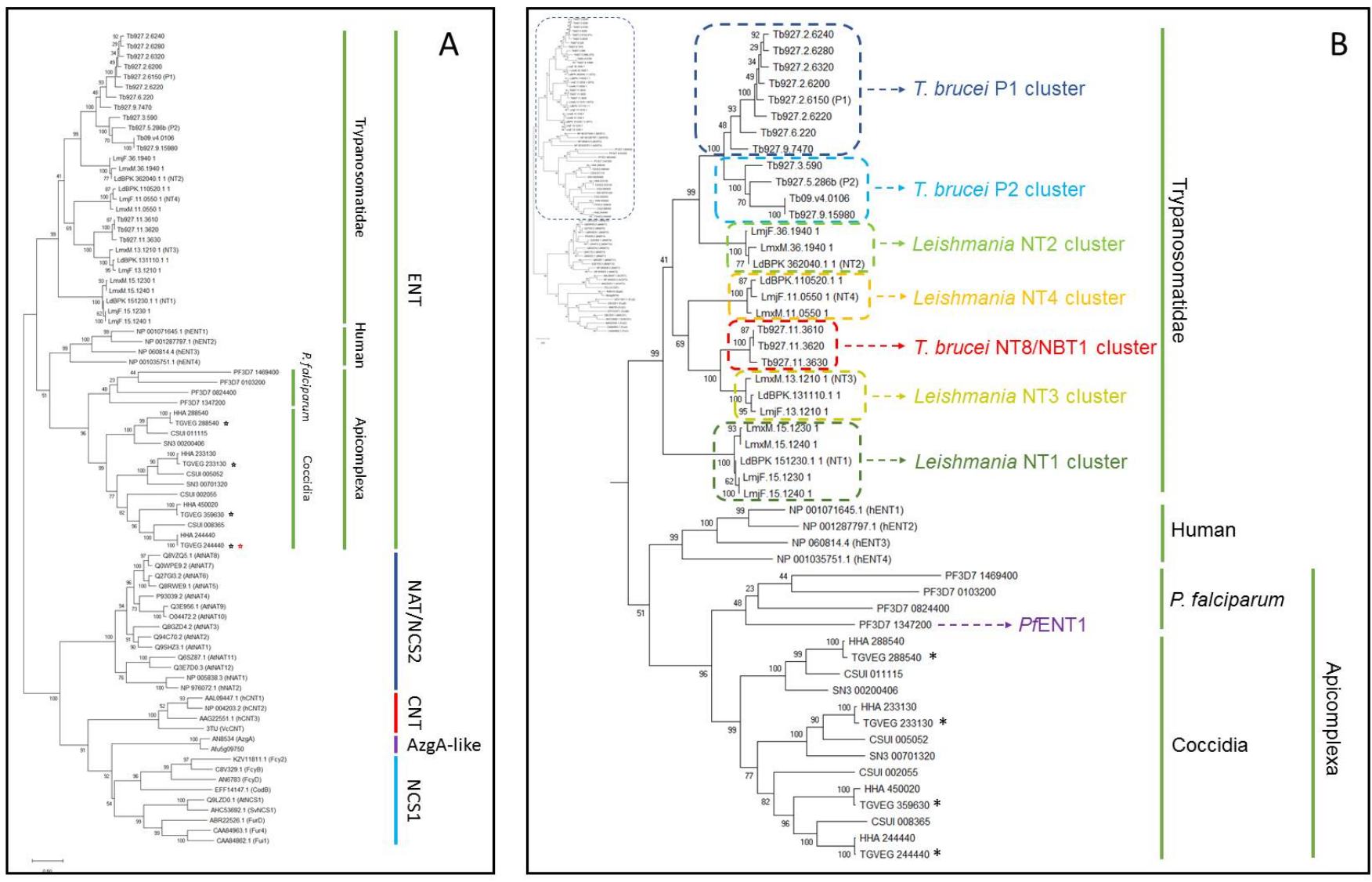

Figure 1. Phylogenetic tree of nucleoside and nucleobase transporters, constructed from a Clustal Omega amino acid multiple alignment by a Maximum Likelihood analysis in Mega-X (500 bootstraps). (A) Overview of division into different gene families. (B) Zoom-in on the ENT (SLC29) gene family, highlighting some well-characterised transporters. All sequences are listed in Supplemental Table S4. * highlights the position of the T. gondii ENT transporters.

\subsection{Tg244440 Is a High-Affinity Oxopurine Transporter}

To understand the role of $\operatorname{Tg} 244440$ in purine transport, we transfected this gene into procyclic forms of the T. brucei TbNB-KO strain that has a null background for the uptake of guanine (and a much-reduced background for hypoxanthine uptake), through the knockout of the locus containing the three nucleobase transporters Tb927.11.3610, Tb927.11.3620, Tb927.11.3630 [32,36]. T. brucei also have a near-null background for thymidine uptake at low concentrations [37,38]. Three clones transfected with Tg244440 (B11, F5 and G10) were randomly picked and used for a screen of substrate transport ability, using $0.1 \mu \mathrm{M}$ of either $\left[{ }^{3} \mathrm{H}\right]$-adenosine, $\left[{ }^{3} \mathrm{H}\right]$-guanine, $\left[{ }^{3} \mathrm{H}\right]$-hypoxanthine or $\left[{ }^{3} \mathrm{H}\right]$-thymidine for $60 \mathrm{~s}$, in comparison to TbNB-KO transfected with empty pHD1336 (EV) (Figure 2). All three TbNB-KO + Tg244440 clones showed highly significant increases in the levels of guanine and hypoxanthine uptake whereas uptake of thymidine was only slightly increased, and only in clone F5. No difference in the transport of adenosine was observed but TbNBT-KO procyclics retain the high-affinity adenosine/inosine/guanosine P1 transporters [39], which gives a high background in the assays using radiolabelled adenosine, as evidenced by the high uptake rate for adenosine compared to the other $\left[{ }^{3} \mathrm{H}\right]$-permeants (Figure 2). Clone F5 was selected for all further experimentation. 

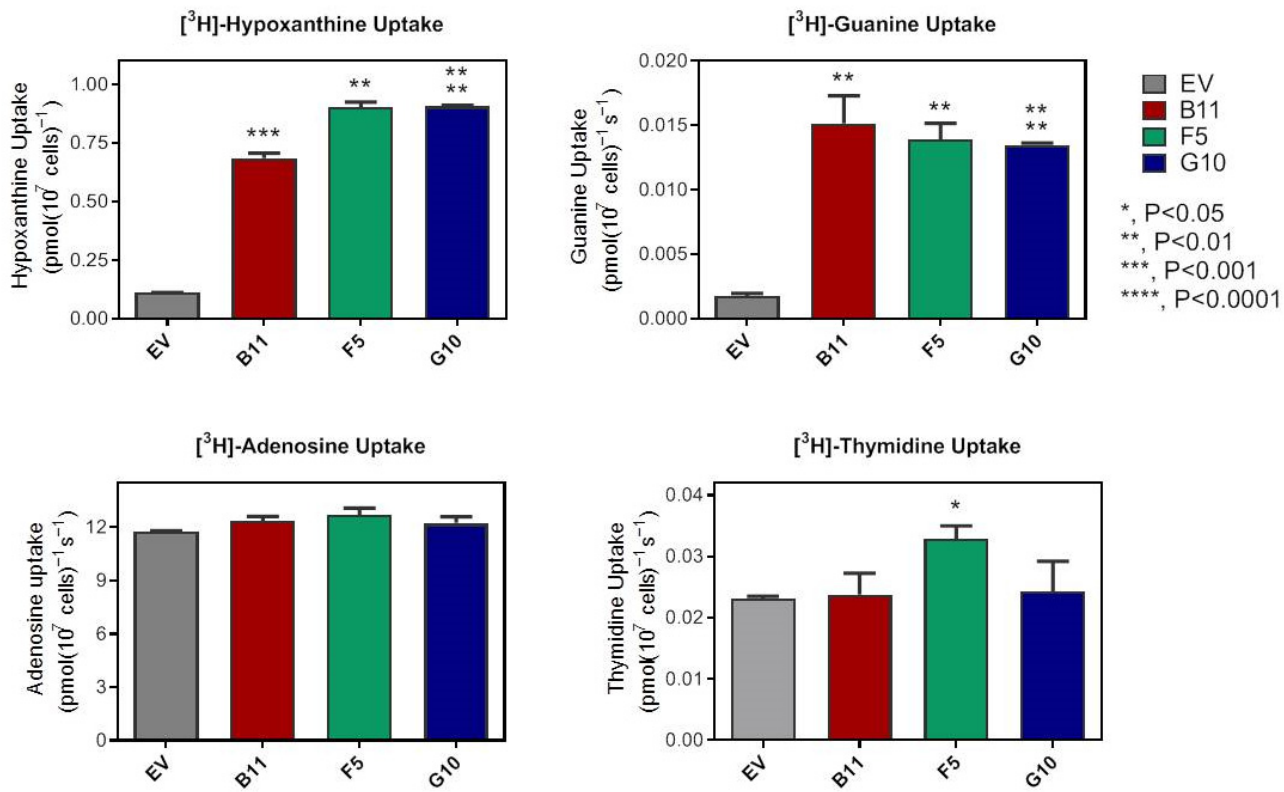

Figure 2. Uptake of radiolabelled nucleosides and nucleobases by in three clonal lines of T. brucei NBKO procyclics, expressing Tg244440 in pHD1336. EV, empty vector control. Radiolabel concentration was $0.1 \mu \mathrm{M}$ and uptake was measured over $60 \mathrm{~s}$, in triplicate (average and SEM shown). Statistically significant differences between the control and the Tg244440-expressing cells were established using Student's unpaired $t$-test. ${ }^{*}, p<0.05,{ }^{* *}, p<0.01,{ }^{* * *}, p<0.001$.

In order to determine the linear phase of substrate uptake we incubated TbNB-KO cells expressing Tg244440 or transfected with the empty vector pHD1336 with $50 \mathrm{nM}$ of $\left[{ }^{3} \mathrm{H}\right]$-guanine or $100 \mathrm{nM}$ of $\left[{ }^{3} \mathrm{H}\right]$-hypoxanthine for predetermined time intervals. The uptake of $\left[{ }^{3} \mathrm{H}\right]$-guanine in the cells expressing Tg244440 was linear for $60 \mathrm{~s}$ (Table 1, Figure 3A). In the presence of $25 \mu \mathrm{M}$ unlabelled guanine there was no significant uptake of the label. In the control cells without the Tg244440 transporter (empty vector, EV), the uptake over $60 \mathrm{~s}$ was also not significantly non-zero (Table 1 ).

Table 1. Increase in the rate of $\left[{ }^{3} \mathrm{H}\right]$-guanine and $\left[{ }^{3} \mathrm{H}\right]$-hypoxanthine uptake in TbNBT-KO cells transfected with the empty vector (EV) or Tg244440 (clone F5).

\begin{tabular}{|c|c|c|c|c|c|c|c|}
\hline \multirow[b]{2}{*}{ Substrate } & \multirow{2}{*}{$\begin{array}{c}\text { [Permeant] } \\
(\mu \mathrm{M})\end{array}$} & \multicolumn{6}{|c|}{ Rate (pmol(10 ${ }^{7}$ Cells) $)^{-1} \mathbf{s}^{-1} \pm$ SD) } \\
\hline & & EV & $\begin{array}{c}P_{1} \\
\text { (Non-Zero) }\end{array}$ & $\begin{array}{c}P_{2} \\
\text { (Non-Linear) }\end{array}$ & $+\operatorname{Tg} 244440$ & $\begin{array}{c}P_{1} \\
\text { (Non-Zero) }\end{array}$ & $\begin{array}{c}P_{2} \\
\text { (Non-Linear) }\end{array}$ \\
\hline \multirow{2}{*}{ Guanine } & 0.05 & $0.0 .00059 \pm 0.900026$ & 0.11 & 0.90 & $0.037 \pm 0.003$ & 0.0012 & $>0.99$ \\
\hline & $25 *$ & $0.0015 \pm 0.0002$ & 0.05 & $>0.99$ & $0.00092 \pm 0.00067$ & 0.40 & $>0.99$ \\
\hline \multirow{2}{*}{ Hypoxanthine } & 0.1 & $0.0066 \pm 0.0007$ & 0.012 & $>0.99$ & $0.048 \pm 0.0004$ & $<0.0001$ & $>0.99$ \\
\hline & $1000 *$ & 0.00055 & $\mathrm{~N} / \mathrm{A}$ & $\mathrm{N} / \mathrm{A}$ & $-0.01 \pm 0.01$ & $\mathrm{~N} / \mathrm{A}$ & $\mathrm{N} / \mathrm{A}$ \\
\hline
\end{tabular}

$P_{1}$ : significantly non-zero slope? F-test (Prism 9.2). $P_{2}$ : significantly non-linear? Runs test (Prism 9.2). ${ }^{*}$ High concentrations of unlabelled guanine or hypoxanthine used to saturate the studied transporter. N/A, not applicable.

Hypoxanthine uptake was very similar to that of guanine: linear over $60 \mathrm{~s}$, saturable, and with a significantly non-zero rate (Table 1 ). The slope of the EV control was also nonzero, as previously reported [32] but $86.2 \%$ lower than the $+\mathrm{Tg} 244440$ clone F5 $(p<0.0001)$ (Figure 3B). We conclude that Tg244440 efficiently transports guanine and hypoxanthine but at best marginally transports thymidine, while no conclusion on adenosine uptake could be reached.

We thus proceeded to determine the affinity of $\operatorname{Tg} 244440$ for hypoxanthine and guanine, and found it to have equally high affinity for both oxopurine nucleobases, with $K_{\mathrm{m}}$ values of $0.79 \pm 0.06 \mu \mathrm{M}$ and $1.26 \pm 0.16 \mu \mathrm{M}$, respectively $(\mathrm{n}=3$, not significantly different, $p=0.099$, unpaired $t$-test) (Figure 4A,B). $\operatorname{Tg} 244440$ showed a clear preference for oxopurine 
nucleobases, as it interacted better with xanthine (Figure $4 \mathrm{~A}$ ), with a $K_{\mathrm{i}}$ of $42.4 \pm 4.2 \mu \mathrm{M}$ $(n=3)$, than with adenine, which was poorly recognised by the transporter (Figure $4 \mathrm{~B})$, with a $K_{\mathrm{i}}$ of $425 \pm 80 \mu \mathrm{M}(\mathrm{n}=8)$ (Table 2$)$.

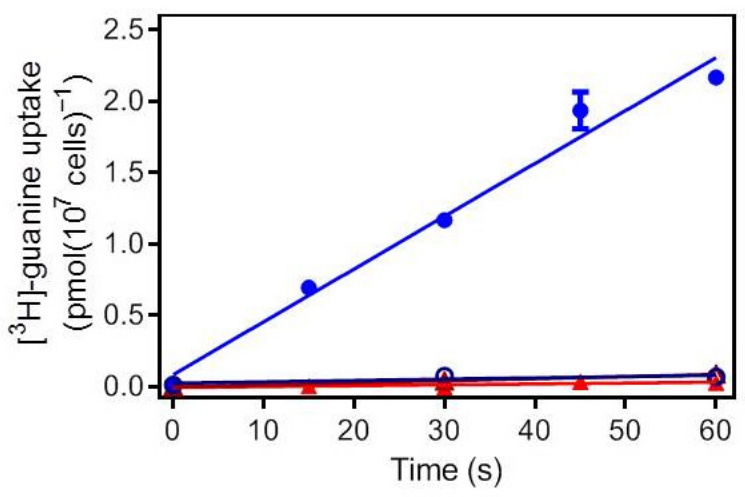

A

^ TbNB-KO + EV

TbNB-KO + EV

$\Delta+25 \mu \mathrm{M}$ guanine

- TbNB-KO + Tg244440

- TbNB-KO + Tg244440

$+25 \mu \mathrm{M}$ guanine

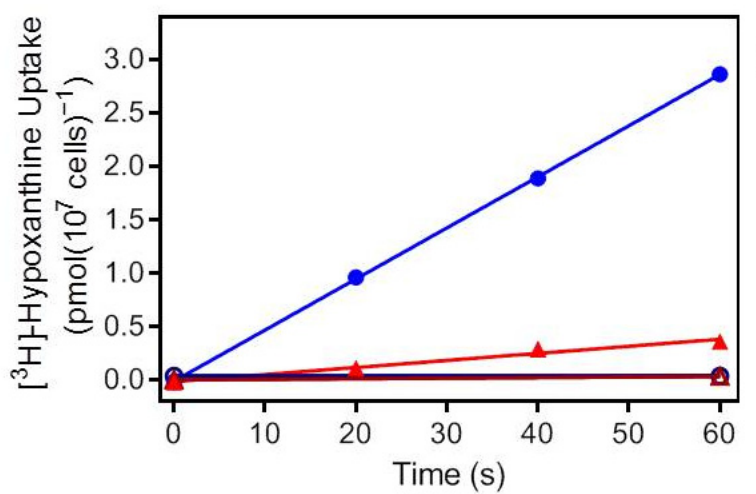

$B$

\ TbNB-KO + EV

$\Delta \quad \mathrm{TbNB}-\mathrm{KO}+\mathrm{EV}$

+1 mM hypoxanthine

- $\mathrm{TbNB}-\mathrm{KO}+\mathrm{Tg} 244440$

- TbNB-KO + Tg244440

$+1 \mathrm{mM}$ hypoxanthine

Figure 3. Uptake of oxopurine nucleobases by $\mathrm{Tg} 244440$ expressed in T. brucei NB-KO procyclics. (A) Uptake of $0.05 \mu \mathrm{M}\left[{ }^{3} \mathrm{H}\right]$-guanine over $60 \mathrm{~s}$. The rate of uptake in the cells expressing $\mathrm{Tg} 244440$ was $0.037 \mathrm{pmol}\left(10^{7} \text { cells }\right)^{-1} \mathrm{~s}^{-1}$ and 0.00059 in the EV control. Both rates were not significantly non-linear $(p>0.90$, runs test); uptake in the control was not significantly non-zero ( $p=0.11$, F-test), whereas the rate in $+\operatorname{Tg} 244440$ cells was significantly non-zero $(p=0.0012)$, but not in the presence of $25 \mu \mathrm{M}$ unlabelled guanine $(p=0.40)$. (B) Uptake of $0.10 \mu \mathrm{M}\left[{ }^{3} \mathrm{H}\right]$-hypoxanthine over $60 \mathrm{~s}$. Rate was 0.0066 and $0.048 \mathrm{pmol}\left(10^{7} \text { cells }\right)^{-1} \mathrm{~s}^{-1}$ for EV control and $+\mathrm{Tg} 2444440$ cells, respectively. Both lines were not significantly non-linear $(p>0.99)$ and significantly non-zero $(p=0.012$ and $p<0.0001$, respectively). Each symbol represents the average and SEM of triplicate determinations.

Interestingly, purine nucleosides were also recognised by the transporter and showed the same trend observed for their respective nucleobases: guanosine and inosine were strongly preferred over adenosine. Indeed, as for hypoxanthine and guanine, the transporter displayed statistically identical $K_{\mathrm{i}}$ values for inosine and guanosine $(4.05 \pm 1.37 \mu \mathrm{M}$ $(\mathrm{n}=4)$ and $3.30 \pm 0.3 \mu \mathrm{M}(\mathrm{n}=7)$, respectively), only slightly higher than the $K_{\mathrm{m}}$ for their corresponding nucleobases, whereas the affinity for adenosine was about 20-fold lower (Figure 4C). In contrast, Tg244440 displayed 6-fold higher affinity for adenosine than for adenine (Table 2).

Pyrimidine nucleobases and nucleosides showed very little affinity for Tg244440 as none of them was able to completely block the transport of $0.1 \mu \mathrm{M}\left[{ }^{3} \mathrm{H}\right]$-guanine at $1 \mathrm{mM}$ and only uridine and thymine displayed any significant inhibition at this concentration $(p<0.05), 10,000$-fold higher than that of the radiopermeant (Figure 4D). We thus conclude $\operatorname{Tg} 244440$ is a high-affinity oxopurine transporter, with particular affinity for guanine and hypoxanthine, that poorly recognises aminopurines and shows no affinity for pyrimidines at physiologically relevant levels. 
Frames A-C: Single experiments in triplicate, representative of three or more identical experiments; for number of replicate determinations for each inhibitor (Table 2).
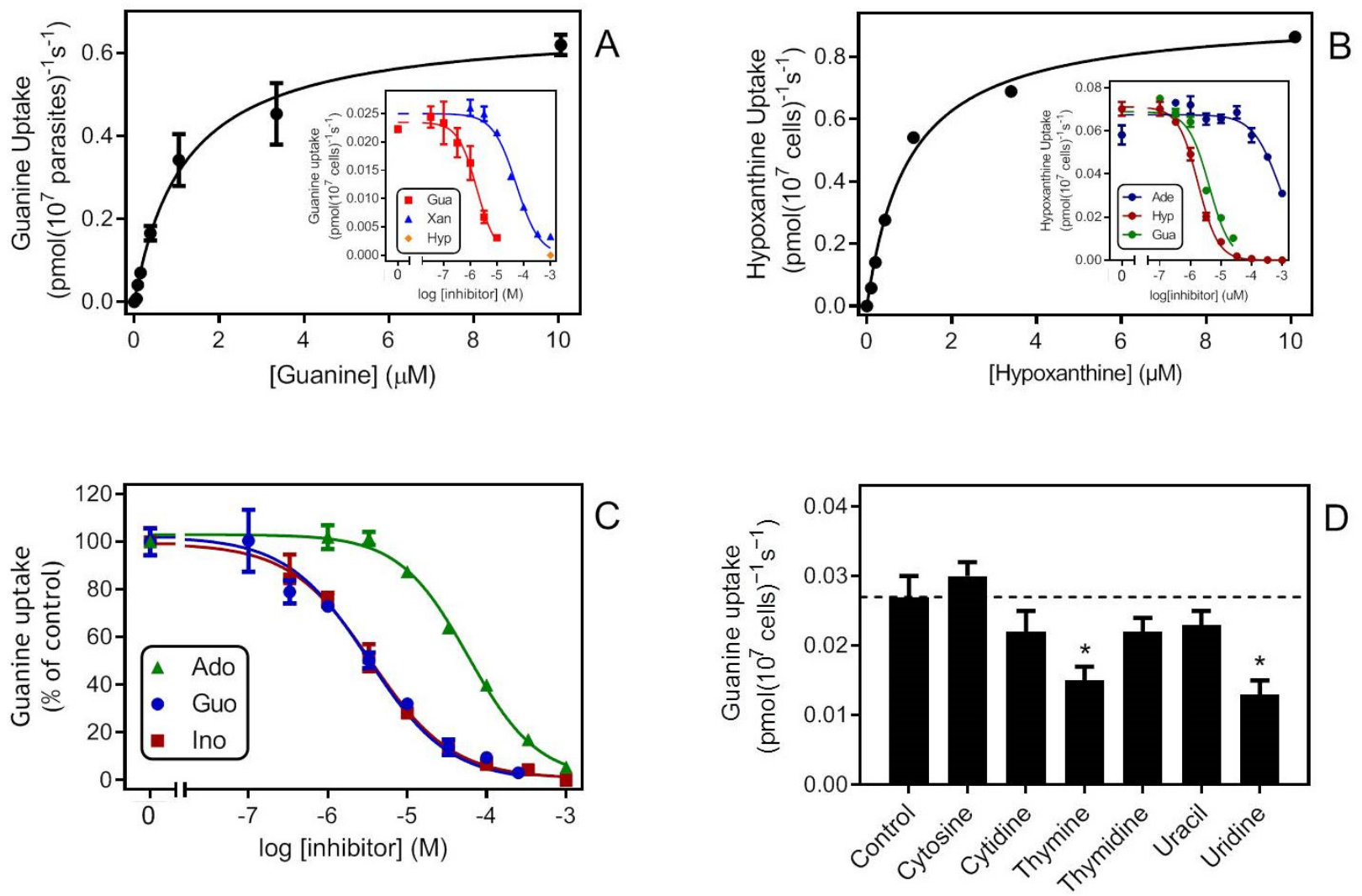

Figure 4. (A) Uptake of $0.05 \mu \mathrm{M}\left[{ }^{3} \mathrm{H}\right]$-guanine over $30 \mathrm{~s}$. Main graph: Michaelis-Menten saturation curve. Inset: shows the dose-dependent inhibition curves of the same experiment, for guanine (Gua), xanthine (Xan) and a single saturation point for hypoxanthine (Hyp). (B) Uptake of $0.10 \mu \mathrm{M}$ $\left[{ }^{3} \mathrm{H}\right]$-hypoxanthine over $30 \mathrm{~s}$. Main graph: Michaelis-Menten saturation curve. Inset: dose-dependent inhibition curves of the same experiment (ade = adenine). (C) Inhibition of $0.05 \mu \mathrm{M}\left[{ }^{3} \mathrm{H}\right]$-guanine over $30 \mathrm{~s}$ by unlabelled purine nucleosides adenosine (Ado), guanosine (Guo) and inosine (Ino). (D) Uptake of $0.05 \mu \mathrm{M}\left[{ }^{3} \mathrm{H}\right]$-guanine over $30 \mathrm{~s}$ inhibited by pyrimidine nucleosides or nucleobases. Each bar is the average and SEM of 3-5 independent experiments, each performed in triplicate. Statistical difference with the control (empty vector pHD1336) was determined by Student's unpaired $t$-test. ${ }^{*}, p<0.05$.

Table 2. Tg244440 Michaelis-Menten constant ( $K_{\mathrm{m}}$, guanine), inhibition constants $\left(K_{\mathrm{i}}\right)$ and Gibbs Free Energy of interaction $\left(\Delta G^{0}\right)$ for various purine analogues. The structure of each purine and purine analogue is shown in Supplemental Table S3.

\begin{tabular}{cccccc}
\hline & $\begin{array}{c}\boldsymbol{K}_{\mathbf{m}} \text { or } \mathbf{K}_{\mathbf{i}} \\
(\boldsymbol{\mu} \mathbf{M})\end{array}$ & $\mathbf{n}$ & $\begin{array}{c}\Delta \mathrm{G}^{\mathbf{0}} \\
(\mathbf{k J} / \mathbf{m o l})\end{array}$ & $\begin{array}{c}\delta\left(\Delta \mathrm{G}^{\mathbf{0}}\right) \\
(\mathbf{k J} / \mathbf{m o l})\end{array}$ & Relative to \\
\hline Purine nucleobases & & & & & \\
\hline Guanine & $1.25 \pm 0.16$ & 3 & -33.7 & & \\
\hline Hypoxanthine & $2.26 \pm 0.36$ & 4 & -32.2 & 1.5 & Guanine \\
\hline Xanthine & $42.4 \pm 4.2$ & 3 & -24.9 & 8.7 & Guanine \\
\hline Adenine & $425 \pm 80$ & 8 & -19.2 & 13.0 & Hypoxanthine \\
\hline 6-Chloropurine & $109 \pm 8$ & 4 & -22.6 & 9.6 & Hypoxanthine \\
\hline
\end{tabular}


Table 2. Cont.

\begin{tabular}{|c|c|c|c|c|c|}
\hline & $\begin{array}{c}K_{\mathrm{m}} \text { or } K_{\mathrm{i}} \\
(\mu \mathrm{M})\end{array}$ & $\mathbf{n}$ & $\begin{array}{c}\Delta \mathrm{G}^{0} \\
(\mathrm{~kJ} / \mathrm{mol})\end{array}$ & $\begin{array}{c}\delta\left(\Delta \mathrm{G}^{0}\right) \\
(\mathrm{kJ} / \mathrm{mol})\end{array}$ & Relative to \\
\hline 6-Mercaptopurine & $3.60 \pm 0.80$ & 3 & -31.1 & 1.2 & Hypoxanthine \\
\hline 6-Thioguanine & $1.64 \pm 0.25$ & 3 & -33.0 & 0.7 & Guanine \\
\hline 1-deazahypoxanthine & $194 \pm 43$ & 5 & -21.2 & 11.0 & Hypoxanthine \\
\hline 1-methylhypoxanthine & $86.2 \pm 7.8$ & 4 & -23.2 & 9.0 & Hypoxanthine \\
\hline 2,6-diaminopurine & $211 \pm 3.5$ & 3 & -21.0 & -1.7 & Adenine \\
\hline 3-deazahypoxanthine & $59.5 \pm 7.2$ & 4 & -24.1 & 8.1 & Hypoxanthine \\
\hline 3-methylxanthine & $14.6 \pm 3.1$ & 4 & -27.6 & -2.7 & Xanthine \\
\hline 7-deazahypoxanthine & $318 \pm 30$ & 4 & -20.0 & 12.3 & Hypoxanthine \\
\hline 7-deazaguanine & $49.2 \pm 5.8$ & 4 & -24.6 & 9.1 & Guanine \\
\hline Allopurinol & $185 \pm 15$ & 4 & -21.3 & 10.9 & Hypoxanthine \\
\hline 7-Br-allopurinol & $65.7 \pm 3.7$ & 3 & -23.9 & -2.5 & Allopurinol \\
\hline Aminopurinol & $223 \pm 27$ & 3 & -20.8 & -1.6 & Adenine \\
\hline 8-azahypoxanthine & $>1000$ & 2 & $<-17.1$ & $>15.1$ & Hypoxanthine \\
\hline 9-deazahypoxanthine & $9.12 \pm 0.66$ & 3 & -28.8 & 3.5 & Hypoxanthine \\
\hline 9-deazaguanine & $9.64 \pm 1.59$ & 4 & -28.6 & 5.1 & Guanine \\
\hline 9-deazaxanthine & $48.2 \pm 5.4$ & 3 & -24.6 & 0.3 & Xanthine \\
\hline 9-Me,1-deazahypoxanthine & $>1000$ & 2 & $<-17.1$ & $>15.1$ & Hypoxanthine \\
\hline \multicolumn{6}{|l|}{ Purine nucleosides } \\
\hline Guanosine & $3.30 \pm 0.30$ & 7 & -31.3 & 2.4 & Guanine \\
\hline Inosine & $4.05 \pm 1.37$ & 4 & -30.8 & 1.4 & Hypoxanthine \\
\hline Adenosine & $68.18 \pm 2.86$ & 5 & -23.8 & -4.5 & Adenine \\
\hline $2^{\prime}$-deoxyinosine & $117 \pm 12$ & 4 & -22.4 & 8.3 & Inosine \\
\hline 3'-deoxyinosine & $102 \pm 15$ & 3 & -22.8 & 8.0 & Inosine \\
\hline $2^{\prime}, 3^{\prime}$-dideoxyinosine & $698 \pm 52$ & 3 & -18.0 & 12.8 & Inosine \\
\hline 5'-deoxyinosine & $35.3 \pm 3.0$ & 3 & -25.4 & 5.4 & Inosine \\
\hline $2^{\prime}$-deoxyguanosine & $281 \pm 6$ & 3 & -20.3 & 11.0 & Guanosine \\
\hline 3'-deoxyguanosine & $196 \pm 12$ & 3 & -21.2 & 10.1 & Guanosine \\
\hline 2'-deoxyadenosine & $83.9 \pm 6.2$ & 4 & -23.3 & 0.5 & Adenosine \\
\hline 3'-deoxyadenosine & $71.9 \pm 2.3$ & 3 & -23.6 & 0.1 & Adenosine \\
\hline 5'-deoxyadenosine & $85.2 \pm 4.2$ & 3 & -23.2 & 0.6 & Adenosine \\
\hline $3^{\prime}$-deoxy,7-deazaadenosine & $797 \pm 116$ & 3 & -17.7 & 6.1 & Adenosine \\
\hline Adenine arabinoside (Ara-A) & $310 \pm 14.0$ & 3 & -20.0 & -3.8 & Adenosine \\
\hline 1-deazainosine & $524 \pm 53$ & 3 & -18.7 & 12.1 & Inosine \\
\hline 1-deazaadenosine & $191 \pm 10$ & 3 & -21.2 & 2.6 & Adenosine \\
\hline 3-deazaadenosine & $1220 \pm 140$ & 3 & -16.6 & 7.2 & Adenosine \\
\hline Nebularine & $491 \pm 75$ & 3 & -18.9 & 4.9 & Adenosine \\
\hline 6-thioinosine & $7.3 \pm 1.2$ & 4 & -29.3 & 1.4 & Inosine \\
\hline 6-O-methyl,7-deaza,7-Cl-inosine & $39.6 \pm 2.8$ & 3 & -25.1 & 5.7 & Inosine \\
\hline 6-O-ethyl,7-deaza,7-Cl-inosine & $169 \pm 10$ & 3 & -21.5 & 9.2 & Inosine \\
\hline
\end{tabular}


Table 2. Cont.

\begin{tabular}{|c|c|c|c|c|c|}
\hline & $\begin{array}{c}K_{\mathrm{m}} \text { or } K_{\mathrm{i}} \\
(\mu \mathrm{M})\end{array}$ & $\mathbf{n}$ & $\begin{array}{c}\Delta \mathrm{G}^{0} \\
(\mathrm{~kJ} / \mathrm{mol})\end{array}$ & $\begin{array}{c}\delta\left(\Delta \mathrm{G}^{0}\right) \\
(\mathrm{kJ} / \mathrm{mol})\end{array}$ & Relative to \\
\hline 7-deazainosine & $6.32 \pm 0.32$ & 3 & -29.7 & 1.1 & Inosine \\
\hline 7-deaza-7-Chloroinosine & $8.9 \pm 1.3$ & 3 & -28.8 & 1.9 & Inosine \\
\hline 7-deaza-7-Bromoinosine & $7.8 \pm 1.2$ & 3 & -29.2 & 1.6 & Inosine \\
\hline 7-deaza-2'-deoxyinosine & $52.3 \pm 8.4$ & 3 & -24.4 & -2.0 & 2'-Deoxyinosine \\
\hline 7-deaza-3'-deoxyinosine & $70.8 \pm 11.2$ & 3 & -23.7 & -0.9 & 3'-Deoxyinosine \\
\hline S-(4-nitrobenzyl)-6-thioinosine (NBMPR) & $78 \pm 6$ & 3 & -23.4 & 0.35 & Adenosine \\
\hline
\end{tabular}

\subsection{Tg244440 Binds Purine Nucleobases and Nucleosides in Different Manners}

In order to better understand the affinity of $\mathrm{Tg} 244440$ for oxopurines over aminopurines, and its intriguing higher affinity for adenosine than for adenine, we sought to investigate which functional groups of the substrates are involved in the interactions with the transporter. To do so, several commercial and newly synthesised analogues of purine nucleobases and nucleosides, with modifications at different positions, were used in competition to $50 \mathrm{nM}$ of $\left[{ }^{3} \mathrm{H}\right]$-guanine to determine the Gibbs free energy $\left(\Delta \mathrm{G}^{0}\right)$ of each interaction between transporter and substrate, exactly as described for multiple other transporters $[29,35,40-43]$. All $K_{i}$ and $\Delta G^{0}$ values are listed in Table 2.

\subsubsection{Binding of Purine Nucleobases}

Given the difference in the high affinity of $\operatorname{Tg} 244440$ for guanine and hypoxanthine as opposed to the low affinity for adenine, we first investigated the participation of the keto group on $\mathrm{C} 6$ and of the protonation state of N1. We found that the presence of the 6-keto group was not important per se given that 6-mercaptopurine and 6-thioguanine (Table 2), which form double bonds with $\mathrm{C} 6$ that keep N1 protonated, showed statistically identical $K_{i}$ values as hypoxanthine $(p=0.17)$ and guanine $(p=0.35)$, respectively, although the sulphur is unable to make a strong hydrogen bond. In contrast, 6-chloropurine, in which N1 is unprotonated, was a poor inhibitor of Tg244440 compared to hypoxanthine $\left(p=5.8 \times 10^{-7}\right)$ and displayed a large difference in Gibbs free energy $\left(\delta\left(\Delta \mathrm{G}^{0}=9.6 \mathrm{~kJ} / \mathrm{mol}\right)\right)$, consistent with the loss of an H-bond involving protonated N1. To verify this conclusion we determined the affinity of $\mathrm{Tg} 244440$ for 1-methylhypoxanthine and 1-deazahypoxanthine, and found a similar loss in Gibbs free energy $(9 \mathrm{~kJ} / \mathrm{mol}$ and $11 \mathrm{~kJ} / \mathrm{mol}$, respectively, relative to hypoxanthine, Table 2).

We previously observed good in vitro and in vivo antiprotozoal potential of purine nucleobase analogues carrying a toxophore on C2 [44,45], and we thus decided to investigate whether Tg244440 could tolerate different C2 modifications. The 2-amine did not interact positively or negatively with the transporter as the affinities for guanine and hypoxanthine were almost identical $(p=0.10)$, as were the $K_{i}$ values of adenine and 2,6-diaminopurine $(p=0.17)$. Xanthine, featuring a 2-keto group, did display a significantly lower $K_{i}$ value than hypoxanthine $\left(p=7.8 \times 10^{-6}, \delta\left(\Delta \mathrm{G}^{0}\right)=7.3 \mathrm{~kJ} / \mathrm{mol}\right)$ but this could be the result of the protonation of N3 in xanthine. Indeed, 3-deazahypoxanthine displayed a similar loss in binding energy $\left(\delta\left(\Delta G^{0}\right)=8.1 \mathrm{~kJ} / \mathrm{mol}\right)$, which confirms the positive contribution of N3 as an H-bond acceptor. Furthermore, the observation that 3-methylxanthine displayed somewhat higher affinity than xanthine $\left(\delta\left(\Delta \mathrm{G}^{0}\right)=2.7 \mathrm{~kJ} / \mathrm{mol} ; p=0.006\right)$ was also consistent with unprotonated N3 being the form contributing to binding. Thus, we conclude that the presence of small substitutions on C2 does not affect the interaction with Tg244440 as long as N3 remains unprotonated.

N7 was also found to be involved in the binding of substrates to Tg244440 as 7deazaguanine $(p=0.0028)$ and 7-deazahypoxanthine $\left(p=6.1 \times 10^{-5}\right)$ showed significantly lower affinity for the transporter $\left(\delta\left(\Delta \mathrm{G}^{0}\right)=9.1\right.$ and $12.3 \mathrm{~kJ} / \mathrm{mol}$, respectively). Moreover, a Nitrogen atom shift from position seven of hypoxanthine to position eight (al- 
lopurinol) caused a significant drop in affinity $\left(p=1.2 \times 10^{-6}\right)$, which resembles that of 7 -deazaadenosine $(p=0.092)$, showing that a nitrogen at position eight is unable to make a similar H-bond as N7. Interestingly, the addition of a bromide on C7 of allopurinol (7-Brallopurinol) recovered $2.5 \mathrm{~kJ} / \mathrm{mol}$ in Gibbs free energy, similar to what has been observed for the T. brucei P1 transporter in which the addition of 7-bromo substantially improves the affinity for $3^{\prime}$-deoxytubercidin [46]. The addition of an extra nitrogen on position eight (8-azahypoxanthine) seems to be highly deleterious to binding by the transporter, as $1 \mathrm{mM}$ of 8-azahypoxanthine failed to inhibit even $50 \%$ of the transport of $50 \mathrm{nM}\left[{ }^{3} \mathrm{H}\right]$-guanine.

The 9-deaza analogues of guanine and hypoxanthine also displayed significantly lower affinity than their 9-aza counterparts $\left(p=0.012,5.1 \mathrm{~kJ} / \mathrm{mol}\right.$ and $p=5.1 \times 10^{-5}$, $3.5 \mathrm{~kJ} / \mathrm{mol}$, respectively). It should be noted that the protonation state of the purine ring nitrogens is part of tautomeric equilibria that are functions of $\mathrm{pH}$ and buffer composition, and may be somewhat different in guanine and hypoxanthine, and could contribute to the small differences in $\delta\left(\Delta G^{0}\right)$ in their 7-deaza and 9-deaza analogues. However, the sum of $\delta\left(\Delta G^{0}\right)$ for the 7-deaza and 9-deaza analogues was very similar for guanine and hypoxanthine at 14.2 and $15.8 \mathrm{~kJ} / \mathrm{mol}$, respectively. Figure $5 \mathrm{~A}$ shows a model for the binding modes of hypoxanthine and guanine. Summation of the Gibbs free energy of the four proposed interactions yields totals of -33.5 and $-31.9 \mathrm{~kJ} / \mathrm{mol}$, respectively, very close to the $\Delta \mathrm{G}^{0}$ values directly calculated from their respective $K_{i}$ and $K_{m}$ values obtained with $\left[{ }^{3} \mathrm{H}\right]$-guanine and $\left[{ }^{3} \mathrm{H}\right]$-hypoxanthine (Table 2 ).

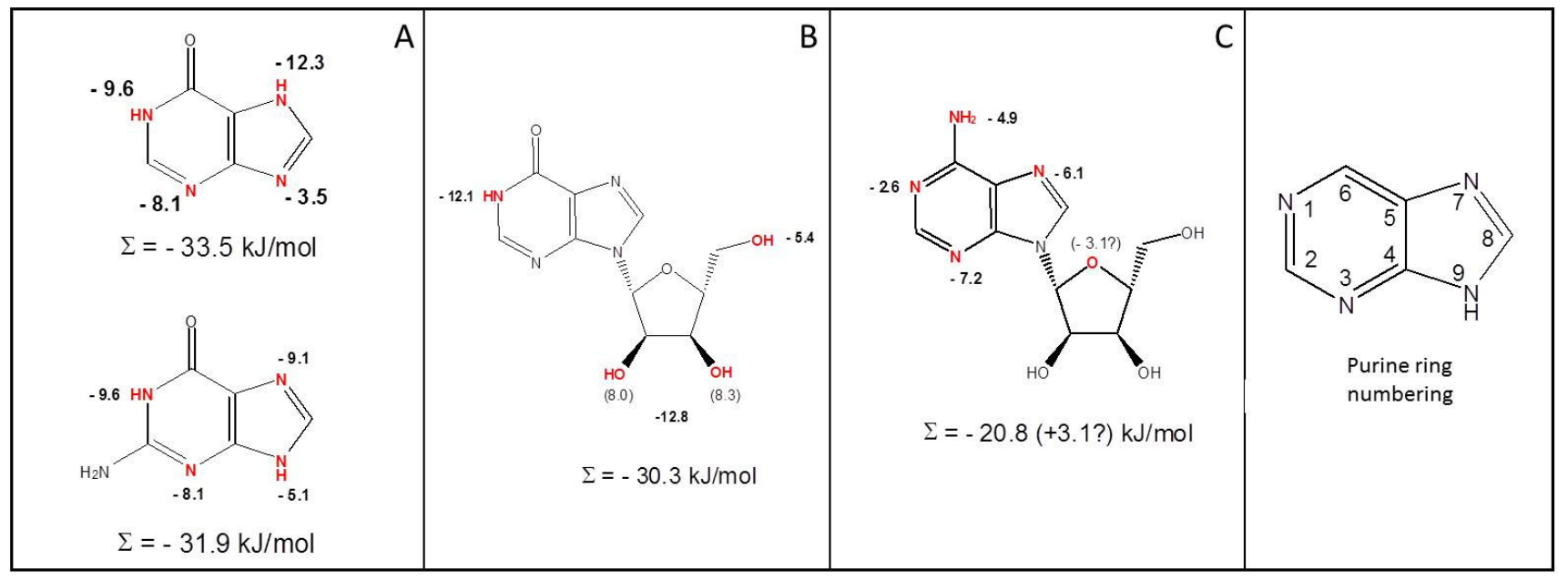

Figure 5. Substrate binding models for Tg244440. (A) Hypoxanthine (top) and guanine (bottom). (B) Inosine. (C) Adenosine. Inset: numbering of purine ring positions. Oval dashed lines represent proposed bonds, presumed to be hydrogen bonds; the numbers given with them are the estimated Gibbs free energy of interaction, in kJ/mol.

\subsubsection{Binding of Purine Nucleosides}

The $\Sigma\left(\delta\left(\Delta G^{0}\right)\right)$ values for hypoxanthine and guanine are also close to the values of the corresponding nucleosides inosine and guanosine, in which, however, N9 would be unable to make any contribution through hydrogen bonds. In T. brucei, the P2/TbAT1 aminopurine transporter binds adenosine only through the adenine moiety, tolerating rather than requiring the ribose half of the molecule [40,47]. For TbAT1, the ribose hydroxyl groups and ring oxygen do not make a positive contribution to nucleoside binding-indeed 2 -deoxy and $3^{\prime}$-deoxyadenosine display somewhat higher affinity than adenosine, virtually identical to adenine $[40,48]$. To test whether the nucleoside binding mode of Tg244440 is similar to that situation, with at most a minor contribution to binding from the ribose moiety, we systematically determined the affinity of matched pair deoxy-inosine and deoxy-guanosine analogues. 
Interestingly, inosine analogues lacking $2^{\prime}-\mathrm{OH}, 3^{\prime}-\mathrm{OH}$ or $5^{\prime}-\mathrm{OH}$ showed significantly lower affinity for Tg244440, with losses of $8.3 \mathrm{~kJ} / \mathrm{mol}(p=0.0049), 8.0 \mathrm{~kJ} / \mathrm{mol}\left(p=3.0 \times 10^{-6}\right)$ and $5.4 \mathrm{~kJ} / \mathrm{mol}$ in Gibbs free energy $\left(p=3.2 \times 10^{-4}\right)$, respectively, compared to inosine. Similar results were shown by $2^{\prime}$-Deoxyguanosine and $3^{\prime}$-deoxyguanosine with loss of $11 \mathrm{~kJ} / \mathrm{mol}\left(p=2.9 \times 10^{-12}\right)$ and $9.4 \mathrm{~kJ} / \mathrm{mol}$ in Gibbs free energy $\left(p=1.9 \times 10^{-8}\right)$, respectively, relative to guanosine (Table 2 ). These results show that most likely all three hydroxy groups of oxopurine nucleosides interact with the transporter. The removal of both $2^{\prime}-\mathrm{OH}$ and $3^{\prime}-\mathrm{OH}$ (i.e., $2^{\prime}, 3^{\prime}$-dideoxyinosine, ddI) caused a loss of Gibbs free energy of $12.8 \mathrm{~kJ} / \mathrm{mol}$ compared to inosine $\left(p=4.9 \times 10^{-5}\right)$, which is less than the sum of the energy lost in $2^{\prime}-$ deoxyinosine and $3^{\prime}$-deoxyinosine $(16.3 \mathrm{~kJ} / \mathrm{mol})$. The likely explanation for this is that both hydroxy groups interact with the same amino acid(s) in the binding pocket and the absence of either allows a higher energy interaction with the other. Figure $5 \mathrm{~B}$ therefore shows a contribution of $-12.8 \mathrm{~kJ} / \mathrm{mol}$ for the $2^{\prime}$ and $3^{\prime}$-hydroxys to the binding of inosine, for which a total $\Delta \mathrm{G}^{0}$ of $-30.3 \mathrm{~kJ} / \mathrm{mol}$ was determined (Table 2 ). The difference, $17.5 \mathrm{~kJ} / \mathrm{mol}$, is likely the result of one or more interactions with the hypoxanthine base group.

Given the low affinity of Tg244440 for adenosine, we first investigated the -sixth position. Substituting the keto group by a sulphur on C6, creating 6-thioinosine, had no significant effect on affinity $(p=0.18)$ but the Gibbs free energy of interaction for nebularine (9-( $\beta$-D-ribofuranosyl)purine) was much lower than for inosine $(11.9 \mathrm{~kJ} / \mathrm{mol}$, $p=0.0014)$. The importance of $\mathrm{N} 1(\mathrm{H})$ for binding of inosine was confirmed by the $\Delta \mathrm{G}^{0}$ for 1-deazainosine, which was virtually identical to that of nebularine $(18.7$ versus $18.9 \mathrm{~kJ} / \mathrm{mol}$, $p=0.78$ ). In contrast to the binding of the oxopurine nucleobases, position N7 is certainly not positively involved in the binding of inosine as the $K_{i}$ values for 7-deaza analogues of inosine $(p=0.29)$, of $2^{\prime}$-deoxyinosine $(p=0.019)$ and of $3^{\prime}$-deoxyinosine $(p=0.25)$ were not significantly different for Tg244440 than those of their matched pairs (Table 2). Moreover, 7-Cl and 7-Br analogues of 7-deazainosine still presented binding energies highly similar to inosine ( $p=0.16$ and 0.088 , respectively). The further modification of $O$-methylation and $\mathrm{O}$-ethylation of 7-Cl,7-deazainosine did, however, cause a significant reduction in binding energy, as this changed the protonation state of $\mathrm{N} 1\left(\delta\left(\Delta \mathrm{G}^{0}\right)=5.7\right.$ and $9.2 \mathrm{~kJ} / \mathrm{mol}$, $p=1.4 \times 10^{-4}$ and $2.0 \times 10^{-5}$, respectively). However, the existence of an (energetically unfavourable) tautomeric state resulting in N1 being a hydrogen bond acceptor (as opposed to a hydrogen bond donor in inosine) in the $O$-alkylated analogues gives these ligands a higher binding energy than 1-deazainosine $\left(\delta\left(\Delta \mathrm{G}^{0}\right)=6.4\right.$ and $2.8 \mathrm{~kJ} / \mathrm{mol}, p=0.0018$ and 0.0060 , respectively).

These observations show that the base parts of oxopurine nucleosides interact with Tg244440 through only a single H-bond, to the protonated N1 (Figure 5B), giving a $\Sigma\left(\Delta \mathrm{G}^{0}\right.$ ) of $-30.1 \mathrm{~kJ} / \mathrm{mol}$ for inosine, very close to the experimental value of $-30.8 \mathrm{~kJ} / \mathrm{mol}$. It is abundantly clear from the binding model presented in Figure 5 that the interaction of the oxopurine base with $\operatorname{Tg} 244440$ is very different for inosine and for hypoxanthine/guanine and that the oxopurine nucleosides are predominantly bound through interactions with the ribose hydroxy groups.

The aminopurines adenosine and adenine displayed only moderate to low affinity for $\operatorname{Tg} 244440$, with the $K_{i}$ for adenosine significantly lower than for adenine $(p=0.0083)$. Curiously, the removal of $2^{\prime}-\mathrm{OH}(p=0.067), 3^{\prime}-\mathrm{OH}(p=0.46)$ or $5^{\prime}-\mathrm{OH}(p=0.024)$ of adenosine barely affected its binding to Tg244440 (Table 2), suggesting that they are not involved in the binding of this nucleoside to the transporter. Although it could alternatively be speculated that $2^{\prime}$ - and 3'-deoxyadenosine bind to Tg244440 in slightly different orientations and compensate for the absence of each other, it remains unclear how the ribose moiety contributes to adenosine binding, perhaps through the ring oxygen, but clearly the adenosine binding mode is different from the binding mode of inosine.

Using a series of adenosine analogues, significantly lower affinities were found for nebularine $\left(p=0.7 .4 \times 10^{-4}\right)$, 1-deazaadenosine $\left(p=2.1 \times 10^{-5}\right)$, 3-deazaadenosine $(p=0.0011)$ and $3^{\prime}$-deoxy,7-deazaadenosine $\left(p=0.4 .6 \times 10^{-4}\right)$ (Table 2). Given that $3^{\prime}$-hydroxy appears not to be involved in the binding, the above leads to a model of adenosine bind- 
ing, with $\Sigma\left(\delta\left(\Delta \mathrm{G}^{0}\right)\right)=-20.8 \mathrm{~kJ} / \mathrm{mol}$ for the base group and the balance to the observed $\Delta \mathrm{G}^{0}(3 \mathrm{~kJ} / \mathrm{mol})$, presumably through the unknown interaction with the ribose moiety (Figure 5C). Interestingly, adenine arabinoside (Ara-A) displayed significantly lower Gibbs free energy of binding than adenosine by $3.75 \mathrm{~kJ} / \mathrm{mol}\left(p=1.9 \times 10^{-6}\right)$, raising the possibility that the stereochemical inversion of the $2^{\prime}-\mathrm{OH}$ interferes with a positive interaction with $\operatorname{Tg} 244440$. The binding mode of adenine, being of low affinity, was not investigated in detail.

\section{Discussion}

Every living cell requires purines and pyrimidines as building blocks for their nucleic acids, as energy storage and as intra- and extracellular signalling molecules. T. gondii, like other parasitic protozoa, is unable to synthesise its own purines and relies on the uptake of these nutrients from the host, a property that has been explored for the development of antiparasitic purine analogues [12,16,18,49]. The ability of T. gondii to incorporate exogenous purines, specifically adenosine, has been known for almost four decades [27,50], but the molecular mechanisms of its salvage process are poorly understood.

In its intracellular milieu, T. gondii will have to compete with the host's enzymes for the available nutrients, and free nucleobases and unphosphorylated nucleosides are present at very low concentrations. Thus, intracellular parasites must have evolved nucleobase and nucleoside transporters with particularly high affinity for their substrates, as recently shown for Trypanosoma cruzi [32] and before for Leishmania spp. [42,51], and for the unrelated apicomplexan Plasmodium falciparum [14].

Only two high-affinity purine transporters, TgNBT1 and TgAT2, selective for hypoxanthine and adenosine/inosine, respectively, have been described for $T$. gondii tachyzoites [29]. In addition, a low-affinity adenosine/inosine transporter (TgAT1) with $K_{m}$ values $>100 \mu \mathrm{M}$ for its substrates has been described by multiple researchers [27-29]. It seems unlikely, however, that TgAT1 would be effective for adenosine uptake, given that its $K_{m}$ for adenosine is higher than the $K_{m}$ values of human adenosine kinase $(0.2-0.4 \mu \mathrm{M})$, human adenosine deaminase $(49 \mu \mathrm{M})$ and the main adenosine transporter hENT1 $(40-60 \mu \mathrm{M})$ [52-55].

Schwab et al. [27] had already reported that $T$. gondii tachyzoites are able to rapidly transport inosine and hypoxanthine, and they described an inosine transporter with an apparent $K_{m}$ of $81 \mu \mathrm{M}$; however, the authors also noticed that inosine can be internalised via two different mechanisms. One inosine transport activity was sensitive and one was insensitive to inhibition by adenosine; the latter could be inhibited by high concentrations of formycin B or hypoxanthine.

Chiang et al. [28] then reported that the genes encoding adenosine kinase and TgAT1 (whose cloned sequence is the gene annotated as Tg244440 in ToxoDB.org) are essential for susceptibility to Ara-A, and that TgAT1 is the sole adenosine transporter of T. gondii tachyzoites. Upon expression of Tg244440 in Xenopus laevis oocytes, the authors determined an adenosine $K_{\mathrm{m}}$ of $114 \pm 37 \mu \mathrm{M}$, using $10 \mu \mathrm{M}\left[{ }^{3} \mathrm{H}\right]$-adenosine. This report has always been puzzling to us, as $T$. gondii tachyzoites would be expected not to rely on a very low affinity transporter for their purine salvage. Moreover, although the affinity of TgAT1 for Ara-A had never been measured directly, it is unlikely that the transporter would have higher affinity for this adenosine analogue than for adenosine itself, and therefore the $K_{\mathrm{m}}$ of TgAT1 for Ara-A would have been (at least) around the hundreds of micromolar range, which is confirmed here. Thus, it would be expected that TgAT2, which has much higher adenosine transport capacity than TgAT1 and interacts with Ara-A with a $K_{\mathrm{i}}$ of $2.9 \mu \mathrm{M}$ [29], was even more important in the internalisation of this nucleoside analogue.

The use of high concentrations of radiolabel used in some of the previous studies $[27,28]$ allows only for the detection and characterisation of low affinity transporters, as it saturates the higher affinity carriers. This is particularly a limitation of the 1995 study [27], which used $1 \mu \mathrm{M}$ of $\left[{ }^{3} \mathrm{H}\right]$-adenosine, a concentration too high to reliably detect TgAT2 with its reported $K_{\mathrm{m}}$ of $0.49 \mu \mathrm{M}$ [29], leaving only the low affinity flux. Moreover, the concentration of $20 \mu \mathrm{M}$ of inosine that was used to determine the $K_{m}$ of the inosine 
transporter(s) expressed by tachyzoites would have completely saturated a high-affinity transporter like TgAT2 ( $K_{\mathrm{m}}$ of $0.77 \mu \mathrm{M}$ [29]) and make its identification impossible. Here, we start to address the confusing state of the (all too sparse) literature on this subject, with a thorough characterisation of the $\mathrm{Tg} 244440$ gene, this time expressed in a protozoan cell type with a null background for guanine uptake.

Using radiolabelled substrate concentrations of 50 and $100 \mathrm{nM}$ for guanine and hypoxanthine, respectively, we determined that the transporter encoded by Tg244440 has $K_{\mathrm{m}}$ values of approximately $1 \mu \mathrm{M}$ for these purine nucleobases. Similarly, this transporter was inhibited, with almost as high affinity, by the oxopurine nucleosides inosine and guanosine but only by much higher concentrations of the aminopurines, adenosine and adenine. We therefore conclude that $\mathrm{Tg} 244440$ is an oxopurine-specific transporter, although the adenosine $K_{\mathrm{m}}$ reported by Chiang et al. [28] in X. laevis oocytes is consistent with the value we report here.

The slightly lower affinity for the oxopurine nucleosides over their corresponding bases leads naturally to a hypothesis that $\mathrm{Tg} 244440$ is a nucleobase transporter that largely tolerates the $N(9)-\beta$-D-ribofuranose. However, the higher affinity of adenosine over adenine does not fit this hypothesis and competition experiments with $2^{\prime}-, 3^{\prime}$ - and $5^{\prime}$-deoxyinosine and/or -guanosine showed that the oxopurine nucleosides derive most of their binding energy from interactions through these hydroxy groups. Equally, systematic investigations of the purine ring interactions found that the oxopurine nucleobases interacted with Tg244440 through all four nitrogen positions (N1(H); N3; N7 and N9(H)), presumably with hydrogen bonds, while in the corresponding nucleosides probably only $\mathrm{N} 1(\mathrm{H})$ contributed positively to binding. Furthermore, the binding mode for adenosine was different again, with little apparent involvement of the ribose hydroxy groups but binding contributions from N1, N3, N7 and 6-NH2. The $4.5 \mathrm{~kJ} / \mathrm{mol}$ higher binding energy for adenosine over adenine might be attributable to an interaction with the ribose group but we were unable to ascertain the nature of that interaction. The transporter had at best very low affinity for pyrimidine nucleobases and nucleosides.

It is clear that Tg244440 can bind different classes of purine bases and nucleosides in different ways and is the first protozoan transporter documented to do so. Logically, the transporter either has multiple binding sites or allows the different substrates to orient differently in a single binding pocket. Of these possibilities the former seems unlikely as all the inhibition data were consistent with competitive inhibition and consistently displayed Hill slopes very close to -1 . Moreover, current structural models of ENT family transporters [56] do not allow for multiple nucleoside and/or nucleobase binding sites but do show a rather large substrate-binding cavity deep inside the 11-TMD structure. Interestingly, this allows different binding orientations for the classical inhibitors S-(4nitrobenzyl)-6-thioinosine (NBMPR) and dilazep, using different but overlapping binding sites including the nucleoside-binding pocket [56]. In an example from the Nucleobase Ascorbate Transporter (NAT) family, different binding orientations for xanthine and allopurinol were demonstrated for the UapA transporter of Aspergillus nidulans [57]. Mutations in the binding pocket of this transporter were shown to alter both substrate specificity and substrate orientation [58]. Similarly, a recent study showed that a series of mutations applied to the Escherichia coli XanQ transporter in order to mimic the ancestral XanQ (AncXanQ) altered it from a xanthine-specific carrier to a xanthine/guanine transporter [59]. Moreover, molecular docking simulations predicted two energetically favorable AncXanQguanine binding modes, both of which differed from the mode of interaction between Anc XanQ and xanthine [59].

We conclude that Tg244440 is a broad-specificity, high affinity transporter for oxopurine bases and nucleosides and that this is likely enabled by a versatile architecture of its central binding pocket. As such, the transporter may serve as a conduit for therapeutic oxopurine analogues tailored to its unique selectivity profile and the binding models here presented. However, $2^{\prime}, 3^{\prime}$-dideoxyinosine, which has been shown to have in vitro and in vivo activity against T. gondii [24-26], displayed a $K_{\mathrm{i}}$ of almost $700 \mu \mathrm{M}$ for Tg244440 
and is therefore unlikely to be an efficient substrate of this carrier. Equally, the adenosine analogue Ara-A which is known to have moderate activity against T. gondii [23], also displayed low affinity for Tg244440. Nevertheless, much progress has recently been made in the identification of nucleoside analogues with highly promising antiprotozoal activities [12], including 7-deaza inosines [60], 3'-fluorinated 7-deazapurine nucleosides [61], 7-phenyl tubercidins [62] and pyrazolo[3,4-d]pyrimidine nucleosides [63]. Additionally, it is worth noting that 7-chloro-7-deazainosine and 7-bromo-7-deazainosine displayed high affinity for Tg244440. Our current activities include the characterisation of the other three $T$. gondii ENT transporters and the identification of purine nucleoside antimetabolites against toxoplasmosis.

\section{Materials and Methods}

\subsection{In Vitro Culture of T. gondii}

T. gondii tachyzoites of the RH strain were grown in Human Foreskin Fibroblasts (HFF) and maintained in Dulbecco's Modified Eagle's (DMEM; Life Technologies, Paisley, Renfrewshire, UK) supplemented with $10 \%$ fetal bovine serum and a cocktail of $1 \%(v / v)$ penicillin-streptomycin and L-glutamine (all from Life Sciences), at $37^{\circ} \mathrm{C}$ under $5 \% \mathrm{CO}_{2}$.

\section{2. $m R N A$ Isolation and $c D N A$ Synthesis}

Parasites released from infected cells were pelleted by centrifugation and the RNA was extracted using the RNeasy Mini kit (Qiagen, Manchester, UK) following the manufacturer's recommendations. Any potential contaminant DNA was eliminated by using the TURBO DNA-free Kit (Thermo Fisher, Loughborough, UK). The RNA was precipitated overnight at $-80{ }^{\circ} \mathrm{C}$ using $0.3 \mathrm{M}$ ammonium acetate, washed with $70 \%$ ethanol, resuspended in nuclease-free water and used for cDNA synthesis utilizing the Invitrogen RETROscript Reverse Transcription Kit (Thermo Fisher), following the manufacturer's instructions, and a provided set of random primers.

Tg244440 was amplified from T. gondii cDNA with primers HDK1328 (forward; TTCATCAAGCTTATGAGTACAATCGAAGAGAGAGCC; HindIII) and HDK1329 (reverse; ATGATAGGATCCCTAGTAAGCGAGAGCGAGGTAC; BamHI) using the high-fidelity Phusion DNA polymerase (New England Biolabs) and cloned into pHD1336 [64] after overnight digestion with HindIII and BamHI. The final plasmid was then sequenced and used for transfection into T. brucei.

\subsection{T. brucei Axenic Culture and Genetic Modification}

T. brucei procyclic form (PCF) cells of TbNBT-KO, a clonal line derived from Lister strain 427, from which a locus of three nucleobase transporter in tandem repeat was deleted [32], were cultivated in SDM-79 medium (Life Technologies), supplemented with $7.5 \mu \mathrm{g} / \mathrm{mL}$ of hemin and 10\% of Fetal Bovine Serum (FBS, Biosera, Kansas City, MO, USA) in non-vented plastic bottles at $27^{\circ} \mathrm{C}$. Cells in logarithmic growth were harvested by centrifugation, resuspended in Cytomix buffer and transfected with NotI-linearized plasmid pHD1336 containing the amplified Tg244440 gene from T. gondii. Transfectant cells were selected exactly as reported previously [32].

\subsection{Uptake Assays}

The transport of purines was measured using tritiated guanine $(20 \mathrm{Ci} / \mathrm{mmol}$; American Radiolabeled Chemicals) and hypoxanthine $(12.8 \mathrm{Ci} / \mathrm{mmol}$; Perkin-Elmer) diluted in assay buffer (AB; 33 mM HEPES, $98 \mathrm{mM} \mathrm{NaCl}, 4.6 \mathrm{mM} \mathrm{KCl,} 0.5 \mathrm{mM} \mathrm{CaCl}, 0.07 \mathrm{mM} \mathrm{MgSO}$, $5.8 \mathrm{mM} \mathrm{NaH}_{2} \mathrm{PO}_{4}, 0.03 \mathrm{mM} \mathrm{MgCl}, 23 \mathrm{mM} \mathrm{NaHCO}, 14 \mathrm{mM}$ D-glucose, pH 7.3), in the presence or absence of potential transporter inhibitors at a predetermined concentration, as described previously for Trypanosoma brucei and Leishmania [65,66].

Briefly, PCF cells of T. brucei in logarithmic growth were harvested by centrifugation at $1000 \times g$ for $10 \mathrm{~min}$, washed twice in $\mathrm{AB}$ and then resuspended in fresh buffer at a final density of $10^{8}$ cells $/ \mathrm{mL}$. Cell suspension in the amount of $100 \mu \mathrm{L}$ was added to an equal 
volume of radiolabel solution for a predetermined time at room temperature, after which the reaction was stopped by the addition of $1 \mathrm{~mL}$ of a saturating concentration of ice-cold unlabeled substrate solution in $\mathrm{AB}$ (usually $1 \mathrm{mM}$ hypoxanthine); this was followed by immediate centrifugation through an oil layer $(7: 1(v / v)$ mix of di-n-butylphthalate and mineral oil (Sigma)). Immediately after finishing the assay, all tubes were flash-frozen in liquid nitrogen and the cell pellets were cut into scintillation vials and lysed with a solution of $2 \%$ SDS for one hour under agitation. Then, $3 \mathrm{~mL}$ of scintillation fluid (Scintilogic $\mathrm{U}$, Lablogic) was added to each vial and left agitating overnight on a rocking platform. The next morning, the vials were vigorously shaken to ensure optimal mixing and the scintillation was measured in a 300SL (Hidex) scintillation counter. All assays were carried out in triplicate. All experimental data such as $K_{\mathrm{m}}, K_{\mathrm{i}}$ and $V_{\max }$ values are the average and SEM of at least three separate experiments, each in triplicate, unless otherwise indicated.

Background scintillation was measured in vials containing no cells or radiolabeled substrate, and counts associated with extracellular radiolabel were calculated from samples where cells were briefly incubated with the same concentration of radiolabel, but in the presence of saturating concentrations of non-radiolabeled substrate before centrifugation through oil. The average of the three control replicates was subtracted from each data point.

\subsection{Calculation of Transport Kinetic Parameters}

To determine the $K_{\mathrm{m}}$, cells were incubated with a low, non-saturating concentration of radiolabeled substrate and increasing concentrations of unlabeled substrate for $30 \mathrm{~s}$, a time that falls very much within the linear phase of transport (see the Results section) during which the observed rate reflects the true initial rate of transport rather than intracellular accumulation of substrate, depletion of substrate from the assay buffer or transporter turnover. The resulting transport data was plotted to the Michaelis-Menten equation $\left(V_{0}=V_{\max } \times[\mathrm{S}] /\left(K_{\mathrm{m}}+[\mathrm{S}]\right)\right.$, with $[\mathrm{S}]$ being the substrate concentration, using GraphPad Prism 8.0. The inhibition constants $\left(K_{\mathrm{i}}\right)$ were calculated using the Cheng-Prusoff equation: $K_{\mathrm{i}}=\mathrm{IC}_{50} /\left(1+\left([\mathrm{S}] / K_{\mathrm{m}}\right)\right)$ [67]. $\mathrm{IC}_{50}$ values were obtained from sigmoid dose-response plots with variable slope, using a constant permeant concentration several-fold below the $K_{\mathrm{m}}$ and a variable inhibitor concentration. The Gibbs free energy $\left(\Delta \mathrm{G}^{0}\right)$ of the inhibitortransporter interaction was calculated using the equation $\Delta \mathrm{G}^{0}=-\mathrm{RT} \ln \left(K_{\mathrm{i}}\right)$, in which $\mathrm{R}$ is the gas constant and $\mathrm{T}$ is the absolute temperature of the reaction. It should be noted that these equations apply to competitive inhibitors, which is likely to be the case given (1) all inhibition curves presented Hill slopes consistently close to -1 and, most importantly, (2) no background for $\left[{ }^{3} \mathrm{H}\right]$-guanine uptake (the radiolabeled probe used for transport inhibition assays) was seen in TbNBT-KO cells, evidencing that the heterologous expression of $\mathrm{Tg} 244440$ created a single guanine transport mechanism in these cells.

\subsection{Synthesis of Nucleoside and Nucleobase Analogues}

Nucleosides, nucleobases and nucleoside analogues were obtained from commercial sources where available, itemized in Table S1 of the Supplemental Information. A number of nucleoside analogues were synthesized as described previously (Table S2 of the Supplemental Information) or synthesized through new routes described in Supplemental File S2.

\subsection{Phylogenetic Analysis}

Amino acid sequences of transporters belonging to several purine and pyrimidine transporter families [12] were obtained from genomic data bases, aligned with Clustal Omega [68] and then subjected to a Maximum Likelihood analysis in Mega-X [69] using the Jones-Taylor-Thornton substitution model with 500 bootstraps. All sequences used for the phylogenetic tree, as well as the transporter families they belong to and the organisms they come from, are listed in Supplemental Information Table S4. 
Supplementary Materials: The following supporting information can be downloaded at: https: //www.mdpi.com/article/10.3390/ijms23020710/s1.

Author Contributions: Conceptualization, H.P.d.K.; methodology, G.D.C., F.H., M.J.N. and S.V.C.; formal analysis, G.D.C., F.H. and H.P.d.K.; investigation, G.D.C., H.A.A.E., S.B., M.E.M.A., F.H. and K.L.; resources, S.V.C.; data curation, H.P.d.K.; writing-original draft preparation, G.D.C. and H.P.d.K.; writing-review and editing, F.H., L.S. and S.V.C.; supervision, L.S., S.V.C. and H.P.d.K.; funding acquisition, G.D.C., S.V.C. and H.P.d.K. All authors have read and agreed to the published version of the manuscript.

Funding: This research was funded by Science Without Borders, grant number 206385/2014-5, CNPq, Brazil (scholarship to GDC); the Libyan government (scholarship to HAAE); the European Union (Erasmus+ for SB); the International Association for the Exchange of Students for Technical Experience provided a bursary to MEMA; M.J.N. was funded through a Fellowship from the Saudi Arabian Ministry of Health; F.H. was supported by the Flanders Research Foundation FWO (grant number 1226921 N) and L.S. by a grant from the Medical Research Council, UK, grant number MR/S024573/1.

Institutional Review Board Statement: Not applicable.

Informed Consent Statement: Not applicable.

Conflicts of Interest: The authors declare no conflict of interest. The funders had no role in the following: the design of the study; the collection, analyses, or interpretation of data; the writing of the manuscript; or in the decision to publish the results.

\section{References}

1. Montoya, J.G.; Liesenfeld, O. Toxoplasmosis. Lancet 2004, 363, 1965-1976. [CrossRef]

2. Robert-Gangneux, F.; Dardé, M.-L. Epidemiology of and diagnostic strategies for toxoplasmosis. Clin. Microbiol. Rev. 2012, 25, 264-296. [CrossRef]

3. Innes, E.A. A brief history and overview of Toxoplasma gondii. Zoonoses Public Health 2010, 57, 1-7. [CrossRef]

4. Bowen, L.N.; Smith, B.; Reich, D.; Quezado, M.; Nath, A. HIV-associated opportunistic CNS infections: Pathophysiology, diagnosis and treatment. Nat. Rev. Neurol. 2016, 12, 662-674. [CrossRef]

5. Lindsay, D.S.; Dubey, J.P. Neosporosis, toxoplasmosis, and sarcocystosis in ruminants: An update. Vet. Clin. N. Am. Food Anim. Pract. 2020, 36, 205-222. [CrossRef]

6. Stelzer, S.; Basso, W.; Benavides Silván, J.; Ortega-Mora, L.M.; Maksimov, P.; Gethmann, J.; Conraths, F.J.; Schares, G. Toxoplasma gondii infection and toxoplasmosis in farm animals: Risk factors and economic impact. Food Waterborne Parasitol. 2019,15, e00037. [CrossRef]

7. Khan, K.; Khan, W. Congenital toxoplasmosis: An overview of the neurological and ocular manifestations. Parasitol. Int. 2018, 67, 715-721. [CrossRef]

8. Dunay, I.R.; Gajurel, K.; Dhakal, R.; Liesenfeld, O.; Montoya, J.G. Treatment of toxoplasmosis: Historical perspective, animal models, and current clinical practice. Clin. Microbiol. Rev. 2018, 31, e00057-17. [CrossRef]

9. Alday, H.; Doggett, J. Drugs in development for toxoplasmosis: Advances, challenges, and current status. Drug Des. Devel. Ther. 2017, 11, 273-293. [CrossRef]

10. Montazeri, M.; Mehrzadi, S.; Sharif, M.; Sarvi, S.; Tanzifi, A.; Aghayan, S.A.; Daryani, A. Drug resistance in Toxoplasma gondii. Front. Microbiol. 2018, 9, 2587. [CrossRef]

11. Montazeri, M.; Sharif, M.; Sarvi, S.; Mehrzadi, S.; Ahmadpour, E.; Daryani, A. A systematic review of in vitro and in vivo activities of anti-Toxoplasma drugs and compounds (2006-2016). Front. Microbiol. 2017, 8, 25. [CrossRef]

12. Campagnaro, G.D.; De Koning, H.P. Purine and pyrimidine transporters of pathogenic protozoa-Conduits for therapeutic agents. Med. Res. Rev. 2020, 40, 1679-1714. [CrossRef]

13. De Koning, H.P.; Bridges, D.J.; Burchmore, R.J.S. Purine and pyrimidine transport in pathogenic protozoa: From biology to therapy. FEMS Microbiol. Rev. 2005, 29, 987-1020. [CrossRef]

14. Quashie, N.B.; Dorin-Semblat, D.; Bray, P.G.; Biagini, G.A.; Doerig, C.; Ranford-Cartwright, L.C.; De Koning, H.P. A comprehensive model of purine uptake by the malaria parasite Plasmodium falciparum: Identification of four purine transport activities in intraerythrocytic parasites. Biochem. J. 2008, 411, 287-295. [CrossRef]

15. Cheviet, T.; Lefebvre-Tournier, I.; Wein, S.; Peyrottes, S. Plasmodium purine metabolism and its inhibition by nucleoside and nucleotide analogues. J. Med. Chem. 2019, 62, 8365-8391. [CrossRef]

16. Kim, Y.A.; Rawal, R.K.; Yoo, J.; Sharon, A.; Jha, A.K.; Chu, C.K.; Rais, R.H.; Al Safarjalani, O.N.; Naguib, F.N.M.; el Kouni, M.H. Structure-activity relationships of carbocyclic 6-benzylthioinosine analogues as subversive substrates of Toxoplasma gondii adenosine kinase. Bioorg. Med. Chem. 2010, 18, 3403-3412. [CrossRef] 
17. Rais, R.H.; Al Safarjalani, O.N.; Yadav, V.; Guarcello, V.; Kirk, M.; Chu, C.K.; Naguib, F.N.M.; el Kouni, M.H. 6-benzylthioinosine analogues as subversive substrate of Toxoplasma gondii adenosine kinase: Activities and selective toxicities. Biochem. Pharmacol. 2005, 69, 1409-1419. [CrossRef]

18. Kim, Y.A.; Sharon, A.; Chu, C.K.; Rais, R.H.; Al Safarjalani, O.N.; Naguib, F.N.M.; el Kouni, M.H. Synthesis, biological evaluation and molecular modeling studies of N6-benzyladenosine analogues as potential anti-toxoplasma agents. Biochem. Pharmacol. 2007, 73, 1558-1572. [CrossRef]

19. Kim, Y.A.; Sharon, A.; Chu, C.K.; Rais, R.H.; Al Safarjalani, O.N.; Naguib, F.N.M.; el Kouni, M.H. Structure-activity relationships of 7-deaza-6-benzylthioinosine analogues as ligands of Toxoplasma gondii adenosine kinase. J. Med. Chem. 2008, 51, 3934-3945. [CrossRef]

20. Al Safarjalani, O.N.; Rais, R.H.; Kim, Y.A.; Chu, C.K.; Naguib, F.N.M.; el Kouni, M.H. Carbocyclic 6-benzylthioinosine analogues as subversive substrates of Toxoplasma gondii adenosine kinase: Biological activities and selective toxicities. Biochem. Pharmacol. 2010, 80, 955-963. [CrossRef]

21. Al Safarjalani, O.N.; Rais, R.H.; Kim, Y.A.; Chu, C.K.; Naguib, F.N.M.; el Kouni, M.H. 7-Deaza-6-benzylthioinosine analogues as subversive substrate of Toxoplasma gondii adenosine kinase: Activities and selective toxicities. Biochem. Pharmacol. 2008, 76, 958-966. [CrossRef]

22. Pfefferkorn, E.R.; Bzik, D.J.; Honsinger, C.P. Toxoplasma gondii: Mechanism of the parasitostatic action of 6-thioxanthine. Exp. Parasitol. 2001, 99, 235-243. [CrossRef]

23. Pfefferkorn, E.R.; Pfefferkorn, L.C. Arabinosyl nucleosides inhibit Toxoplasma gondii and allow the selection of resistant mutants. J. Parasitol. 1976, 62, 993-999. [CrossRef]

24. Gherardi, A.; Sarciron, M.E.; Peyron, F. Toxoplasma encephalitis: Influence of the vehicle on the efficacy of different doses of 2',3'-dideoxyinosine in mice. Parasite 2000, 7, 39-42. [CrossRef]

25. Sarciron, M.E.; Lawton, P.; Petavy, A.F.; Peyron, F. Alterations of Toxoplasma gondii induced by $2^{\prime}, 3^{\prime}$-dideoxyinosine in vitro. J. Parasitol. 1998, 84, 1055-1059. [CrossRef]

26. Sarciron, M.E.; Lawton, P.; Saccharin, C.; Petavy, A.F.; Peyron, F. Effects of 2',3'-dideoxyinosine on Toxoplasma gondii cysts in mice. Antimicrob. Agents Chemother. 1997, 41, 1531-1536. [CrossRef]

27. Schwab, J.C.; Afifi Afifi, M.; Pizzorno, G.; Handschumacher, R.E.; Joiner, K.A. Toxoplasma gondii tachyzoites possess an unusual plasma membrane adenosine transporter. Mol. Biochem. Parasitol. 1995, 70, 59-69. [CrossRef]

28. Chiang, C.W.; Carter, N.; Sullivan, W.J.; Donald, R.G.K.; Roos, D.S.; Naguib, F.N.M.; El Kouni, M.H.; Ullman, B.; Wilson, C.M. The adenosine transporter of Toxoplasma gondii. Identification by insertional mutagenesis, cloning, and recombinant expression. J. Biol. Chem. 1999, 274, 35255-35261. [CrossRef]

29. De Koning, H.P.; Al-Salabi, M.I.; Cohen, A.M.; Coombs, G.H.; Wastling, J.M. Identification and characterisation of high affinity nucleoside and nucleobase transporters in Toxoplasma gondii. Int. J. Parasitol. 2003, 33, 821-831. [CrossRef]

30. Alzahrani, K.J.H.; Ali, J.A.M.; Eze, A.A.; Looi, W.L.; Tagoe, D.N.A.; Creek, D.J.; Barrett, M.P.; De Koning, H.P. Functional and genetic evidence that nucleoside transport is highly conserved in Leishmania species: Implications for pyrimidine-based chemotherapy. Int. J. Parasitol. Drugs Drug Resist. 2017, 7, 206-226. [CrossRef]

31. Munday, J.C.; Rojas López, K.E.; Eze, A.A.; Delespaux, V.; Van Den Abbeele, J.; Rowan, T.; Barrett, M.P.; Morrison, L.J.; De Koning, H.P. Functional expression of TcoAT1 reveals it to be a P1-type nucleoside transporter with no capacity for diminazene uptake. Int. J. Parasitol. Drugs Drug Resist. 2013, 3, 69-76. [CrossRef] [PubMed]

32. Campagnaro, G.D.; de Freitas Nascimento, J.; Girard, R.B.M.; Silber, A.M.; De Koning, H.P. Cloning and characterisation of the Equilibrative Nucleoside Transporter family of Trypanosoma cruzi: Ultra-high affinity and selectivity to survive in the intracellular niche. Biochim. Biophys. Acta Gen. Subj. 2018, 1862, 2750-2763. [CrossRef] [PubMed]

33. Natto, M.J.; Munday, J.C.; AlSiari, T.A.; Quashie, N.B.; Eze, A.A.; Ahmed, W.; Karra, V.; Eckmann, L.; De Koning, H.P. Trichomonas vaginalis: Overview of nucleoside and nucleobase transport activities and functional cloning of a trichomonad nucleoside transporter. Mol. Microbiol. 2021, in press. [CrossRef]

34. Chaliotis, A.; Vlastaridis, P.; Ntountoumi, C.; Botou, M.; Yalelis, V.; Lazou, P.; Tatsaki, E.; Mossialos, D.; Frillingos, S.; Amoutzias, G. NAT/NCS2-hound: A webserver for the detection and evolutionary classification of prokaryotic and eukaryotic nucleobase-cation symporters of the NAT/NCS2 family. GigaScience 2018, 7, 1-8. [CrossRef]

35. Papakostas, K.; Botou, M.; Frillingos, S. Functional identification of the hypoxanthine/guanine transporters YjcD and YgfQ and the adenine transporters PurP and YicO of Escherichia coli K-12. J. Biol. Chem. 2013, 288, 36827-36840. [CrossRef]

36. Walzer, K.A.; Adomako-Ankomah, Y.; Dam, R.A.; Herrmann, D.C.; Schares, G.; Dubey, J.P.; Boyle, J.P. Hammondia hammondi, an avirulent relative of Toxoplasma gondii, has functional orthologs of known T. gondii virulence genes. Proc. Natl. Acad. Sci. USA 2013, 110, 7446-7451. [CrossRef]

37. Ali, J.A.M.; Creek, D.J.; Burgess, K.; Allison, H.C.; Field, M.C.; Mäser, P.; De Koning, H.P. Pyrimidine salvage in Trypanosoma brucei bloodstream forms and the trypanocidal action of halogenated pyrimidines. Mol. Pharmacol. 2013, 83, 439-453. [CrossRef]

38. Gudin, S.; Quashie, N.B.; Candlish, D.; Al-Salabi, M.I.; Jarvis, S.M.; Ranford-Cartwright, L.C.; De Koning, H.P. Trypanosoma brucei: A survey of pyrimidine transport activities. Exp. Parasitol. 2006, 114, 118-125. [CrossRef]

39. De Koning, H.P.; Watson, C.J.; Jarvis, S.M. Characterization of a nucleoside/proton symporter in procyclic Trypanosoma brucei brucei. J. Biol. Chem. 1998, 273, 9486-9494. [CrossRef] 
40. De Koning, H.P.; Jarvis, S.M. Adenosine transporters in bloodstream forms of Trypanosoma brucei brucei: Substrate recognition motifs and affinity for trypanocidal drugs. Mol. Pharmacol. 1999, 56, 1162-1170. [CrossRef]

41. Wallace, L.J.M.; Candlish, D.; De Koning, H.P. Different substrate recognition motifs of human and trypanosome nucleobase transporters. Selective uptake of purine antimetabolites. J. Biol. Chem. 2002, 277, 26149-26156. [CrossRef] [PubMed]

42. Al-Salabi, M.I.; De Koning, H.P. Purine nucleobase transport in amastigotes of Leishmania mexicana: Involvement in allopurinol uptake. Antimicrob. Agents Chemother. 2005, 49, 3682-3689. [CrossRef] [PubMed]

43. Al-Salabi, M.I.; Wallace, L.J.; Luscher, A.; Mäser, P.; Candlish, D.; Rodenko, B.; Gould, M.K.; Jabeen, I.; Ajith, S.N.; De Koning, H.P. Molecular interactions underlying the unusually high adenosine affinity of a novel Trypanosoma brucei nucleoside transporter. Mol. Pharmacol. 2007, 71, 921-929. [CrossRef]

44. Rodenko, B.; Wanner, M.J.; Alkhaldi, A.A.M.; Ebiloma, G.U.; Barnes, R.L.; Kaiser, M.; Brun, R.; McCulloch, R.; Koomen, G.J.; De Koning, H.P. Targeting the parasite's DNA with methyltriazenyl purine analogs is a safe, selective, and efficacious antitrypanosomal strategy. Antimicrob. Agents Chemother. 2015, 59, 6708-6716. [CrossRef] [PubMed]

45. Vodnala, S.K.; Lundbäck, T.; Yeheskieli, E.; Sjöberg, B.; Gustavsson, A.L.; Svensson, R.; Olivera, G.C.; Eze, A.A.; De Koning, H.P.; Hammarström, L.G.J.; et al. Structure-activity relationships of synthetic cordycepin analogues as experimental therapeutics for Africa trypanosomiasis. J. Med. Chem. 2013, 56, 9861-9873. [CrossRef]

46. Hulpia, F.; Mabille, D.; Campagnaro, G.D.; Schuman, G.; Maes, L.; Roditi, I.; Hofer, A.; De Koning, H.P.; Caljon, G.; Van Calenbergh, S. Combining the tubercidin and cordycepin scaffolds results in highly active candidates for the treatment of late stage sleeping sickness. Nat. Commun. 2019, 10, 5564. [CrossRef] [PubMed]

47. Munday, J.C.; Settimo, L.; De Koning, H.P. Transport proteins determine drug sensitivity and resistance in a protozoan parasite, Trypanosoma brucei. Front. Pharmacol. 2015, 6, 32. [CrossRef]

48. Collar, C.J.; Al-Salabi, M.I.; Stewart, M.L.; Barrett, M.P.; Wilson, W.D.; De Koning, H.P. Predictive computational models of substrate binding by a nucleoside transporter. J. Biol. Chem. 2009, 284, 34028-34035. [CrossRef]

49. El Kouni, M.H. Adenosine metabolism in Toxoplasma gondii: Potential targets for chemotherapy. Curr. Pharm. Des. 2007, 13, 581-597. [CrossRef]

50. Schwartzman, J.D.; Pfefferkorn, E.R. Toxoplasma gondii: Purine synthesis and salvage in mutant host cells and parasites. Exp. Parasitol. 1982, 53, 77-86. [CrossRef]

51. Ghosh, M.; Mukherjee, T. Stage-specific development of a novel adenosine transporter in Leishmania donovani amastigotes. Mol. Biochem. Parasitol. 2000, 108, 93-99. [CrossRef]

52. Boison, D. Adenosine kinase: Exploitation for therapeutic gain. Pharmacol. Rev. 2013, 65, 906-943. [CrossRef]

53. Daddona, P.E.; Wiesmann, W.P.; Lambros, C.; Kelley, W.N.; Webster, H.K. Human malaria parasite adenosine deaminase. Characterization in host enzyme-deficient erythrocyte culture. J. Biol. Chem. 1984, 259, 1472-1475. [CrossRef]

54. Ward, J.L.; Sherali, A.; Mo, Z.P.; Tse, C.M. Kinetic and pharmacological properties of cloned human equilibrative nucleoside transporters, ENT1 and ENT2, stably expressed in nucleoside transporter-deficient PK15 cells. ENT2 exhibits a low affinity for guanosine and cytidine but a high affinity for inosine. J. Biol. Chem. 2000, 275, 8375-8381.

55. Griffith, D.A.; Jarvis, S.M. Nucleoside and nucleobase transport systems of mammalian cells. Biochim. Biophys. Acta Rev. Biomembr. 1996, 1286, 153-181. [CrossRef]

56. Wright, N.J.; Lee, S.-Y. Structures of human ENT1 in complex with adenosine reuptake inhibitors. Nat. Struct. Mol. Biol. 2019, 26, 599-606. [CrossRef] [PubMed]

57. Diallinas, G. Allopurinol and xanthine use different translocation mechanisms and trajectories in the fungal UapA transporter Biochimie 2013, 95, 1755-1764. [CrossRef]

58. Kourkoulou, A.; Zantza, I.; Foti, K.; Mikros, E.; Diallinas, G. Context-dependent cryptic roles of specific residues in substrate selectivity of the UapA purine transporter. J. Mol. Biol. 2021, 433, 166814. [CrossRef]

59. Tatsaki, E.; Anagnostopoulou, E.; Zantza, I.; Lazou, P.; Mikros, E.; Frillingos, S. Identification of new specificity determinants in bacterial purine nucleobase transporters based on an ancestral sequence reconstruction approach. J. Mol. Biol. 2021, $433,167329$. [CrossRef]

60. Hulpia, F.; Bouton, J.; Campagnaro, G.D.; Alfayez, I.A.; Mabille, D.; Maes, L.; De Koning, H.P.; Caljon, G.; Van Calenbergh, S. C6-O-alkylated 7-deazainosine nucleoside analogues: Discovery of potent and selective anti-sleeping sickness agents. Eur. J. Med. Chem. 2020, 188, 112018. [CrossRef]

61. Bouton, J.; Furquim d'Almeida, A.; Maes, L.; Caljon, G.; Van Calenbergh, S.; Hulpia, F. Synthesis and evaluation of 3'-fluorinated 7-deazapurine nucleosides as antikinetoplastid agents. Eur. J. Med. Chem. 2021, 216, 113290. [CrossRef]

62. Natto, M.J.; Hulpia, F.; Kalkman, E.R.; Baillie, S.; Alhejeli, A.; AlSiari, T.; Eckmann, S.; Van Calenbergh, S.; De Koning, H.P. Validation of a resorufin-based in vitro high throughput screen for Trichomonas vaginalis identifies highly potent deazapurine nucleoside analogues with in vivo efficacy. ACS Infect. Dis. 2021, 7, 1752-1764. [CrossRef]

63. Bouton, J.; Ferreira de Almeida Fiuza, L.; Cardoso Santos, C.; Mazzarella, M.A.; de Soeiro, M.N.C.; Maes, L.; Karalic, I.; Caljon, G.; Van Calenbergh, S. Revisiting pyrazolo[3,4-d]pyrimidine nucleosides as anti-Trypanosoma cruzi and antileishmanial agents. J. Med. Chem. 2021, 64, 4206-4238. [CrossRef] [PubMed]

64. Biebinger, S.; Elizabeth Wirtz, L.; Lorenz, P.; Clayton, C. Vectors for inducible expression of toxic gene products in bloodstream and procyclic Trypanosoma brucei. Mol. Biochem. Parasitol. 1997, 85, 99-112. [CrossRef] 
65. Al-Salabi, M.I.; Wallace, L.J.M.; De Koning, H.P. A Leishmania major nucleobase transporter responsible for allopurinol uptake is a functional homolog of the Trypanosoma brucei H2 transporter. Mol. Pharmacol. 2003, 63, 814-820. [CrossRef] [PubMed]

66. Campagnaro, G.D.; Alzahrani, K.J.H.; Munday, J.C.; De Koning, H.P. Trypanosoma brucei bloodstream forms express highly specific and separate transporters for adenine and hypoxanthine; evidence for a new protozoan purine transporter family? Mol. Biochem. Parasitol. 2018, 220, 46-56. [CrossRef] [PubMed]

67. Cheng, Y.-C.; Prusoff, W.H. Relationship between the inhibition constant (KI) and the concentration of inhibitor which causes 50 per cent inhibition (I50) of an enzymatic reaction. Biochem. Pharmacol. 1973, 22, 3099-3108.

68. Madeira, F.; mi Park, Y.; Lee, J.; Buso, N.; Gur, T.; Madhusoodanan, N.; Basutkar, P.; Tivey, A.R.N.; Potter, S.C.; Finn, R.D.; et al. The EMBL-EBI search and sequence analysis tools APIs in 2019. Nucleic Acids Res. 2019, 47, W636-W641. [CrossRef]

69. Kumar, S.; Stecher, G.; Li, M.; Knyaz, C.; Tamura, K. MEGA X: Molecular Evolutionary Genetics Analysis across Computing Platforms. Mol. Biol. Evol. 2018, 35, 1547-1549. [CrossRef] 